\title{
Efeitos da Dexmedetomidina sobre a Coagulação Sangüínea Avaliada através do Método da Tromboelastografia *
}

\section{Effects of Dexmedetomidine on Blood Coagulation Evaluated by Thromboelastography}

César Romão Martins ${ }^{1}$; Maria Angela Tardelli, TSA ${ }^{2}$; José Luiz Gomes do Amaral, TSA ${ }^{3}$

\section{RESUMO}

Martins CR, Tardelli MA, Amaral JLG - Efeitos da Dexmedetomidina sobre a Coagulação Sangüínea Avaliada através do Método da Tromboelastografia

JUSTIFICATIVA E OBJETIVOS: A dexmedetomidina é um agente agonista dos receptores adrenérgicos $\alpha_{2}$ altamente seletivo, usado em anestesia por seus efeitos hipnoanalgésicos e pela estabilidade cardiovascular. O estímulo dos receptores adrenérgicos $\alpha_{2}$ pode apresentar efeitos pró e antiagregantes plaquetários, por mecanismos diretos e indiretos. No presente estudo, avaliaram-se os efeitos da dexmedetomidina sobre a coagulação através do método da tromboelastografia.

MÉTODO: Vinte e quatro pacientes foram aleatoriamente divididos em três grupos. Os pacientes do grupo 1 receberam infusão de solução fisiológica (controle), os do grupo 2 receberam dexmedetomidina na dose de $1 \mu \mathrm{g} \cdot \mathrm{kg}^{-1} \mathrm{em} 10$ minutos, seguida da infusão de $0,4 \mu \mathrm{g} \cdot \mathrm{kg}^{-1} \cdot \mathrm{h}^{-1}$ por 20 minutos e os do grupo 3 receberam midazolam na dose de $0,05 \mathrm{mg}^{\mathrm{kg}}{ }^{-1}$. Os pacientes sedados mantiveram índices 3 ou 4 na escala da sedação de Ramsay. Foram coletadas amostras de sangue e obtidos traçados de tromboelastografia previamente e após 30 minutos do tratamento.

RESULTADOS: A dexmedetomidina, de forma estatisticamente significativa, aumentou o tempo de reação (parâmetro $R$ ) e diminuiu o índice de coagulação nos traçados finais em relação aos iniciais. No entanto, os valores permaneceram dentro dos intervalos considerados normais. Este fenômeno não foi observado nos demais grupos.

CONCLUSÕES: A interação dos mecanismos pró e antiagregantes da dexmedetomidina leva à discreta hipocoagulação; porém, mantém a coagulação dentro de parâmetros considerados normais. Os efeitos da dexmedetomidina sobre a coagulação provavelmente não ocorrem pela ansiólise, uma vez que a sedação foi igual ao grupo que recebeu midazolam.

\footnotetext{
* Recebido da (Received from) Universidade Federal de São Paulo Escola Paulista de Medicina (UNIFESP-EPM), São Paulo, SP; Trabalho vencedor do Prêmio Renato Ribeiro - 2002

1. Anestesiologista; Preceptor dos Residentes do CET da UNIFESP - EPM

2. Professora Adjunta da Disciplina de Anestesiologia, Dor e Terapia Intensiva da UNIFESP - EPM

3. Professor Titular da Disciplina de Anestesiologia, Dor e Terapia Intensiva da UNIFESP - EPM
}

Apresentado (Submitted) em 27 de novembro de 2002

Aceito (Accepted) para publicação em 01 de abril de 2003

Endereço para correspondência (Correspondence to)

Dra. Maria Angela Tardelli

Rua Hastimphilo Moura, 338/A $7 C$

05641-000 São Paulo, SP

(c) Sociedade Brasileira de Anestesiologia, 2003
Unitermos: DROGAS, $\alpha_{2}$-agonista: dexmedetomidina; EXAMES LABORATORIAIS: tromboelastografia; SANGUE: coagulação

\section{SUMMARY}

Martins CR, Tardelli MA, Amaral JLG - Effects of Dexmedetomidine on Blood Coagulation Evaluated by Thromboelastography

BACKGROUND AND OBJECTIVES: Dexmedetomidine is a highly selective $\alpha_{2}$-adrenoceptor agonist used in anesthesia for its hypnoanalgesic and cardiovascular effects. Stimulation of $\alpha_{2}$-adrenoceptors may determine pro and anti-platelet aggregation effects through direct and indirect mechanisms. This study aimed at determining the effects of dexmedetomidine on coagulation evaluated by thromboelastography.

METHODS: Twenty four patients were randomly distributed in 3 groups: Group 1 patients received saline solution (control group), Group 2 patients received $1 \mu \mathrm{g}_{ }{ }^{-1}$ dexmedetomidine in 10 minutes, followed by $0.4 \mu \mathrm{g} \cdot \mathrm{kg}^{-1} . \mathrm{h}^{-1}$ infusion for 20 minutes and Group 3 patients received $0.05 \mathrm{mg} \cdot \mathrm{kg}^{-1}$ midazolam. Sedated patients maintained scores 3 or 4 in Ramsay's sedation scale. Blood samples were collected before and 30 minutes after the treatment for thromboelastography.

RESULTS: Dexmedetomidine has significantly increased reaction time (parameter $R$ ) and decreased coagulation index in final curves as compared to initial ones. Values, however, have remained within ranges accepted as normal. This phenomenon was not observed in remaining groups.

CONCLUSIONS: Dexmedetomidine pro and anti-platelet aggregation mechanisms interaction determines mild hypocoagulation, however maintaining coagulation within normal ranges. Dexmedetomidine effects on coagulation are probably not mediated by anxiolysis, since sedation was equivalent to the midazolam group.

Key Words: BLOOD: coagulation; DRUGS, $\alpha_{2}$-agonist: dexmedetomidine; LABORATIAL TESTS: thromboelastography

\section{INTRODUÇÃO}

A dexmedetomidina é um agente simpatomimético com seletividade de 1/1600 para receptores adrenérgicos $\alpha_{2}$ em relação aos receptores $\alpha_{1}$. Esta ação seletiva sobre receptores $\alpha_{2}$ confere a esta droga propriedades hipnóticas, através da estimulação destes receptores no locus cœrulleus, e analgésicas, através da estimulação destes receptores no corno dorsal da medula ${ }^{1-5}$.

Estas propriedades, aliadas à estabilidade hemodinâmica e à mínima depressão respiratória, tornaram a dexmedetomidina uma opção interessante para sedação em Terapia Intensiva ${ }^{6}$.

A dexmedetomidina também tem sido utilizada na anestesia em ampla variedade de procedimentos. Há relatos da utiliza- 
ção da dexmedetomidina como auxiliar na sedação de procedimentos realizados sob anestesia local até como adjuvante em procedimentos cirúrgicos de grande porte ${ }^{7,8}$. O potencial benefício da utilização da dexmedetomidina durante a anestesia evidencia-se pela vantagem de, frente a potencialização dos agentes hipnoanalgésicos, diminuir a necessidade destes agentes no per-operatório reduzindo, desta forma, seus efeitos colaterais, principalmente os efeitos cardiovasculares e depressores da ventilação ${ }^{9-12}$.

Sabe-se que a estimulação de adrenorreceptores $\alpha_{2}$ por adrenalina ou dexmedetomidina pode, in vitro, induzir a agregação plaquetária ${ }^{13}$. No entanto, in vivo, a dexmedetomidina promove liberação de óxido nítrico (NO) do endotélio vascular ${ }^{4}$ e diminui a liberação de catecolaminas, por retroalimentação negativa, ao estimular os adrenorreceptores $\alpha_{2}$ pré-sinápticos ${ }^{14}$, o que resulta em efeito antiagregante ${ }^{4}$. A utilização de agentes hipnóticos com o intuito de promover ansiólise e sedação durante a anestesia também poderia interferir no processo de coagulação por diminuição da atividade simpática ${ }^{15}$. O efeito final da interação destes fatores sobre a coagulação ainda não foi demonstrado.

A tromboelastografia é um método que permite que se faça uma avaliação da função hemostática a partir de uma pequena amostra de sangue, documentando a interação entre as plaquetas e as proteínas da cascata de coagulação, desde o tempo inicial da interação entre plaquetas e fibrina, passando pela agregação plaquetária, retração do coágulo e sua lise. Os traçados gráficos decorrentes destas interações informam sobre a atividade dos fatores de coagulação, função plaquetária e processo fibrinolítico ${ }^{16}$.

O objetivo deste trabalho foi avaliar os efeitos da dexmedetomidina sobre a coagulação sangüínea através da tromboelastografia e discriminar se seus efeitos sobre a coagulação ocorrem por mecanismos diretos ou indiretos.

\section{MÉTODO}

O presente estudo foi desenvolvido após aprovação pelo Comitê de Ética em Pesquisa da Universidade Federal de São Paulo - Escola Paulista de Medicina.

Foram incluídos no estudo 24 pacientes entre 18 e 45 anos de idade, de ambos os sexos, candidatos a procedimentos operatórios em que a dexmedetomidina ou o midazolam pudessem ser empregados no início do procedimento. Os participantes do estudo assinaram um consentimento, após informação sobre o estudo.

Foram excluídos os pacientes com índice de massa corpórea menor ou igual a $30 \mathrm{~kg} \cdot \mathrm{m}^{-2}$, pacientes com história conhecida ou suspeita de distúrbios de coagulação, os que faziam uso de medicamentos que interferem com a coagulação (ácido acetil-salicílico, antiinflamatórios não-hormonais, Ginko biloba, anticoagulantes orais, heparina ou heparinóides) e pacientes que haviam sido hidratados no pré-operatório imediato com soluções de Ringer, soluções coloidais ou que haviam recebido hemoderivados. Também foram excluídos pacientes com doenças que podem cursar com alteração da coagulação, como neoplasias, grandes lesões tissulares e pacien- tes plaquetopênicos ou com alteração do coagulograma pré-operatório.

Os pacientes foram aleatoriamente distribuídos em três grupos de acordo com o esquema de sedação recebido: G1, grupo controle, que recebeu apenas solução fisiológica ( $\mathrm{NaCl}$ a 0,9\%); G2, grupo que recebeu dexmedetomidina; e G3, grupo que recebeu midazolam.

À chegada na sala de operações, todos os pacientes foram monitorados com cardioscópio de duas derivações, oxímetro de pulso e pressão arterial não-invasiva. Obteve-se um acesso venoso com cateter $20 \mathrm{G}$ em membro superior e iniciou-se a hidratação com solução fisiológica ( $\mathrm{NaCl}$ a 0,9\%), $4 \mathrm{ml} \cdot \mathrm{kg}^{-1} \cdot \mathrm{h}^{-1}$. Procedeu-se a uma punção venosa para coleta de $2 \mathrm{ml}$ de sangue para realização de tromboelastografia de controle. Após esta coleta, aos pacientes do G1, manteve-se apenas a administração da solução fisiológica. Aos pacientes do $\mathrm{G} 2$, iniciou-se a administração de dexmedetomidina na dose de $1 \mu \mathrm{g} . \mathrm{kg}^{-1}$ infundidos em 10 minutos, seguida da administração de dose de manutenção de 0,4 $\mu \mathrm{g} \cdot \mathrm{kg}^{-1} \cdot \mathrm{h}^{-1}$. Aos pacientes do G3 administrou-se 0,05 $\mathrm{mg} . \mathrm{kg}^{-1}$ de midazolam por via venosa. O objetivo da sedação foi manter os pacientes com índices 3 ou 4 da escala de sedação de Ramsay (dormindo, porém despertáveis ao chamado ou à compressão leve da glabela). Após 30 minutos do início da infusão de solução fisiológica para o G1, de dexmedetomidina para o $\mathrm{G} 2$, e do bolus de midazolam para o G3, realizou-se a coleta da segunda amostra de sangue (2 $\mathrm{ml}$ ) para a tromboelastografia.

Tromboelastografia: as amostras de sangue foram colhidas após garroteamento do membro superior e assepsia com álcool $70 \%$ com agulha $30 \times 7$ em seringa de $3 \mathrm{ml}$, num total de 2 $\mathrm{ml}$. Imediatamente era disparado um cronômetro e as amostras eram acondicionadas em frasco seco siliconizado e levadas ao aparelho de tromboelastografia (Thromboelastograph Coagulation Analyzer ${ }^{\circledR}$ - Model 5000 - Haemoscope Corporation). Foram pipetadas amostras de $360 \mu \mathrm{l}$ e colocadas nos copos do aparelho. Os copos eram posicionados para início do exame e o comando no computador para início do traçado era acionado sempre após 1 minuto da coleta.

Os pacientes que apresentassem qualquer alteração no traçado inicial da tromboelastografia, bem como reações indesejáveis atribuídas à dexmedetomidina ou ao midazolam, seriam excluídos do protocolo.

Após a coleta da segunda amostra, os pacientes desvinculavam-se do protocolo, podendo receber qualquer esquema anestésico, a critério do anestesiologista responsável.

Os parâmetros analisados nos traçados da tromboelastografia foram (Figura 1):

1. Tempo de Reação (parâmetro R): tempo decorrido do início do processamento da amostra até que o diagrama TEG atinja $2 \mathrm{~mm}$. É o ponto onde a maioria dos testes tradicionais de coagulação chegam ao fim. Representa o tempo de formação inicial da fibrina e é funcionalmente relacionado aos fatores de coagulação plasmáticos e à atividade dos fatores anticoagulantes circulantes. Pode aumentar nas situações de deficiência de fatores de co- 
agulação, anticoagulação (heparina) ou hipofibrinogenemia grave. Um $\mathrm{R}$ curto relaciona-se a estados de hipercoagulabilidade;

2. Tempo de formação do coágulo (parâmetro $\mathrm{K}$ ): tempo desde o início da formação do coágulo $(R)$ até que o traçado atinja a amplitude de $20 \mathrm{~mm}$. Ké uma medida de cinética do coágulo. Pode ser reduzido pelo aumento do nível de fibrinogênio e, em menor escala, pela função plaquetária. Pode ser prolongado por anticoagulantes que afetem ambos os fatores;

3. Ângulo $\alpha\left(\alpha^{\circ}\right)$ : o ângulo formado pela curva do traçado da TEG do valor de $\mathrm{R}$ até $\mathrm{K}$. Denota a velocidade com que um coágulo sólido é formado. Seu valor diminui na presença de hipofibrinogenemia e hipofunção plaquetária;

4. Amplitude Máxima (AM): maior amplitude alcançada no traçado da TEG. Reflete a firmeza absoluta atingida pelo coágulo. É o parâmetro mais sensível aos distúrbios qualitativos ou quantitativos das plaquetas;

5. Tempo para Amplitude Máxima (TAM): reflete a cinética total da formação do coágulo ou tempo até a formação de um coágulo estável;

6. Firmeza do Coágulo (parâmetro $\mathrm{G}$ ): sensível a pequenas mudanças na resistência ou divisão do coágulo;

7. Lise de Coágulo de Sangue Total (CL30): mede a amplitude do traçado 30 minutos após atingida a amplitude máxima em relação à amplitude máxima;

8. Lise Percentual Estimada (LPE): representa percentualmente a diminuição da amplitude, 30 minutos após atingida a amplitude máxima;

9. Índice de Coagulação (IC): descreve a coagulação geral e é obtido através de uma equação de combinações lineares das variáveis $\mathrm{R}, \mathrm{K}, \mathrm{AM}$ e $\alpha^{\circ}$. Denota um panorama geral da interação de todos os fatores na formação do coágulo.

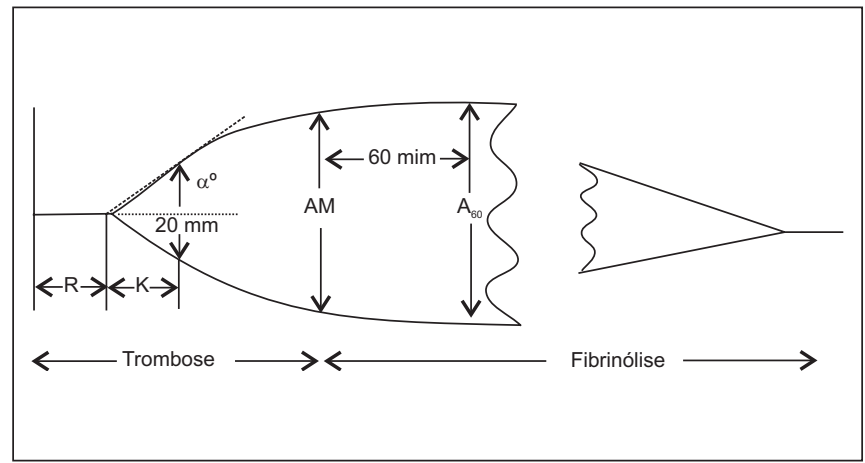

Figura 1 - Quantificação das Variáveis da Tromboelastografia Análise do traçado ${ }^{13} \cdot \mathrm{R}=$ tempo de reação; $\mathrm{K}=$ tempo para o traçado atingir $20 \mathrm{~mm} ; \alpha^{\circ}=$ ângulo formado pela linha que liga $\mathrm{R}$ a K; $\mathrm{AM}=$ amplitude máxima; $\mathrm{A}_{60}=$ amplitude 60 minutos após atingida a amplitude máxima

Os parâmetros demográficos idade e peso foram analisados através do teste $t$ de Student com correção de Bonferroni e a distribuição quanto ao sexo através do teste de proporção de Fisher. Os parâmetros da tromboelastografia foram comparados globalmente através de Análise de
Variância (ANOVA) e os valores pré e pós-tratamento de cada grupo separadamente foram comparados através de teste $\mathrm{T}$ pareado. Considerou-se estatisticamente significante $p<0,05$.

\section{RESULTADOS}

Não houve diferenças estatisticamente significativas entre os dados demográficos dos três grupos (Tabela I).

Tabela I - Dados Demográficos

\begin{tabular}{|c|c|c|c|}
\hline & Controle & Dexmedetomidina & Midazolam \\
\hline Peso $(\mathrm{kg})$ * & $64,5 \pm 8,62$ & $68,9 \pm 10,77$ & $65,6 \pm 9,12$ \\
\hline Idade (anos) * & $34,125 \pm 5,462$ & $34,375 \pm 6,209$ & $34,875 \pm 8,983$ \\
\hline \multicolumn{4}{|l|}{ Sexo } \\
\hline Feminino & 4 & 3 & 4 \\
\hline Masculino & 4 & 5 & 4 \\
\hline
\end{tabular}

* Valores expressos pela Média \pm DP

Não houve diferenças estatisticamente significativas entre a composição dos grupos

Apenas um paciente, originalmente pertencente ao grupo controle, foi excluído por apresentar a curva de tromboelastografia inicial com padrão característico de fibrinólise.

Um paciente do G2 necessitou um incremento da dose de manutenção de dexmedetomidina para $0,5 \mu \mathrm{g} \cdot \mathrm{kg}^{-1} \cdot \mathrm{h}^{-1}$ e um paciente do G3 necessitou receber dose adicional de $1 \mathrm{mg}$ de midazolam para que mantivessem índice 3 ou 4 na escala de sedação de Ramsay.

Os valores do tempo de reação (parâmetro $R$ ), em minutos, nos grupos G1, G2 e G3 iniciais foram 13,43 $\pm 3,13,12,02 \pm$ 4,21 e $12,40 \pm 3,94$ e os valores finais foram 12,06 $\pm 1,99$, $14,92 \pm 2,43$ e 13,87 $\pm 5,02$ (Figura 2). O intervalo de referência para este parâmetro é de 15 a 23 minutos. Em todos os grupos, nas medidas iniciais e finais, os valores de R encontraram-se abaixo do limite inferior considerado normal, porém não houve diferenças estatisticamente significantes entre os grupos quando comparados em conjunto através de análise de variância $(p=0,537)$. Quando se estudaram os grupos separadamente e compararam-se as medidas iniciais com as finais, a dexmedetomidina aumentou o R de forma estatisticamente significante $(p=0,03)$.

Os valores do tempo para o traçado atingir $20 \mathrm{~mm}$ (parâmetro $\mathrm{K}$ ), em minutos, nos grupos G1, G2 e G3 iniciais foram 6,05 \pm $2,17,6,13 \pm 2,25$ e $4,88 \pm 1,54$ e os valores finais foram $5,65 \pm$ $1,33,6,85 \pm 1,62$ e $5,11 \pm 1,69$, respectivamente (Figura 3 ). 0 intervalo de referência para este parâmetro é de 5 a 10 minutos. Apenas nas curvas iniciais do grupo 3 (midazolam) os valores de $\mathrm{K}$ encontravam-se abaixo do limite inferior $(4,88$ $\mathrm{min})$. Nos demais traçados estes valores encontravam-se dentro deste intervalo considerado normal, porém próximos ao limite inferior. Não houve diferenças estatisticamente significantes entre os grupos ou entre as medidas iniciais e finais $(p=0,289)$. 


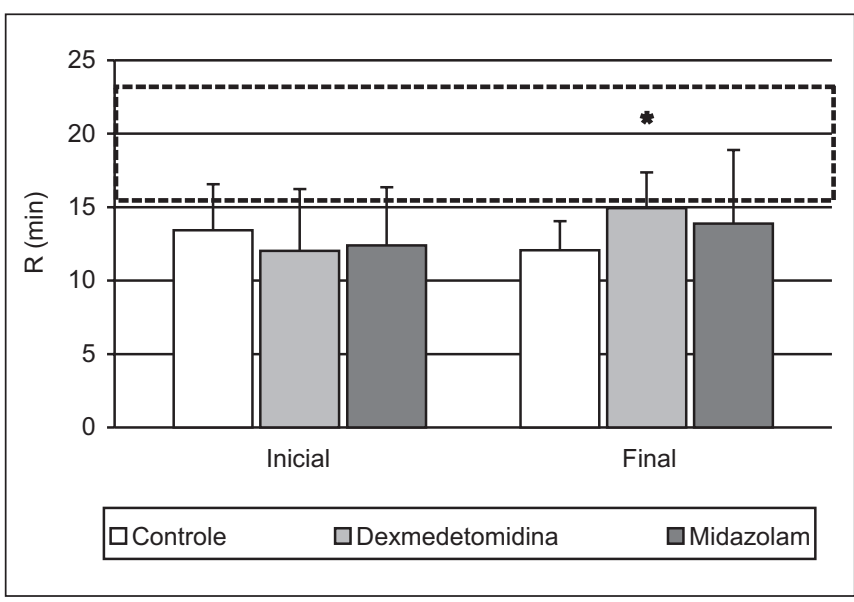

Figura 2 - Valores Iniciais e Finais do Tempo de Reação (parâmetro $\mathrm{R})$, em Minutos

Entre as linhas tracejadas encontram-se os valores de referência

${ }^{*} p \leq 0,05$ em relação ao grupo dexmedetomidina inicial

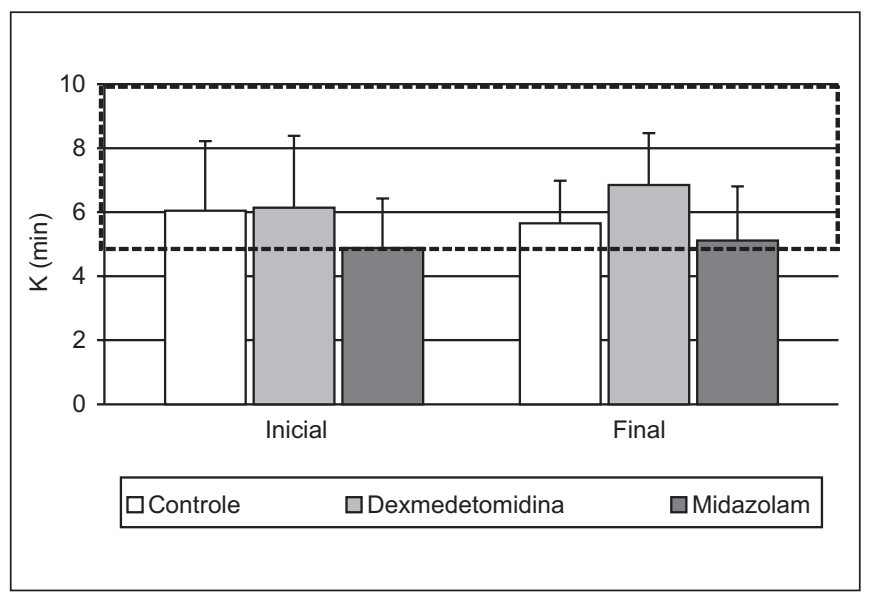

Figura 3 - Valores Iniciais e Finais do Tempo que o Coágulo leva para Atingir $20 \mathrm{~mm}$ (parâmetro $\mathrm{K}$ ou tempo de formação do coágulo), em Minutos

Entre as linhas tracejadas encontram-se os valores de referência. Não houve diferenças estatisticamente significantes

Os valores do ângulo $\alpha$, em graus, nos grupos G1, G2 e G3 iniciais foram $35,93 \pm 10,35,36,43 \pm 12,02$ e $40,87 \pm 8,66$ e os valores finais foram $36,81 \pm 8,55,31,81 \pm 7,01$ e $38,81 \pm$ 10,11 , respectivamente (Figura 4). O intervalo de referência para este parâmetroé de 22 a 38 graus. Nas curvas iniciais do grupo 3 (midazolam), os valores do ângulo $\alpha$ encontravam-se acima do limite superior; porém, mantiveram-se acima deste valor nas curvas finais. Nos demais traçados, estes valores encontravam-se dentro deste intervalo considerado normal; porém, próximos ao limite superior. Não houve diferenças estatisticamente significantes entre os grupos ou entre as medidas iniciais e finais $(p=0,551)$.

Os valores da amplitude máxima (AM), em milímetros, nos grupos G1, G2 e G3 iniciais foram $54,31 \pm 8,02,51,56 \pm 4,52$ e $54,31 \pm 6,95$ e os valores finais foram $56,12 \pm 6,64,48,87 \pm$ 4,41 e $53,93 \pm 6,54$, respectivamente (Figura 5). O intervalo 708

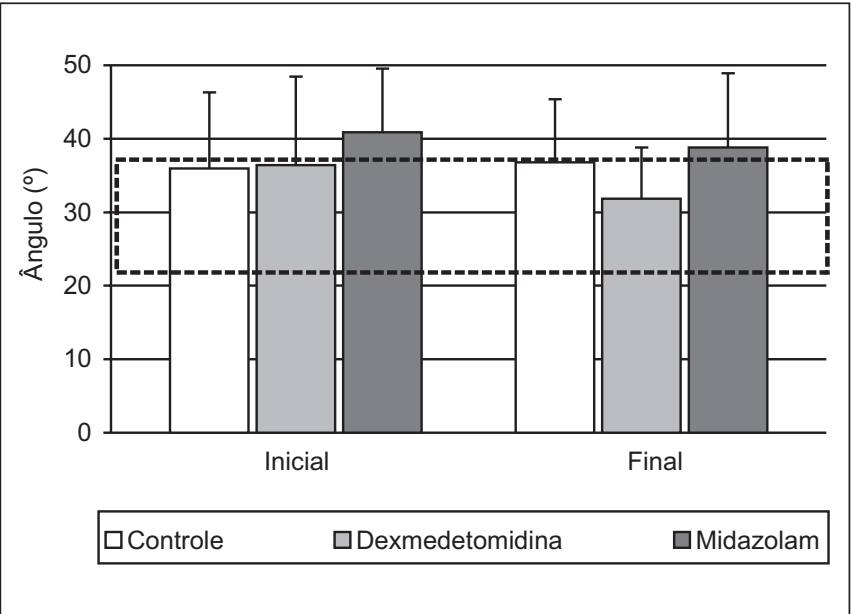

Figura 4 - Valores Iniciais e Finais do Ângulo Alfa $(\alpha)$

Entre as linhas tracejadas encontram-se os valores de referência. Não houve diferenças estatisticamente significantes

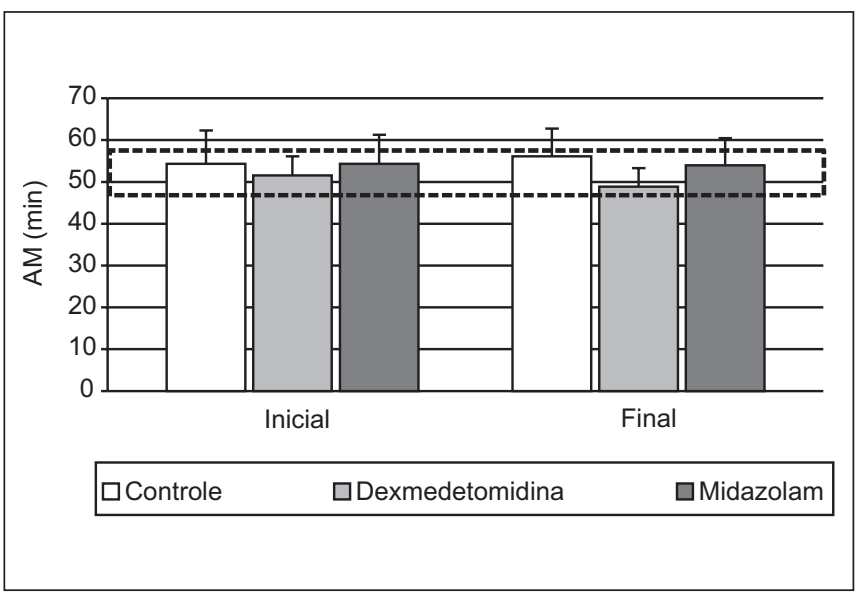

Figura 5 - Valores Iniciais e Finais da Amplitude Máxima (AM) Entre as linhas tracejadas encontram-se os valores de referência. Não houve diferenças estatisticamente significantes

de referência para este parâmetro é de 47 a $58 \mathrm{~mm}$. Em todos os traçados, os valores da AM encontravam-se dentro do intervalo considerado normal. Não houve diferenças estatisticamente significantes entre os grupos ou entre as medidas iniciais e finais $(p=0,274)$.

Os valores do tempo para se atingir a amplitude máxima (TAM), em minutos, nos grupos G1, G2 e G3 iniciais foram $33,00 \pm 6,85,31,36 \pm 6,33$ e $28,51 \pm 1,77$ e os valores finais foram $33,4 \pm 7,06,33,05 \pm 4,09$ e 32,36 $\pm 5,20$, respectivamente (Figura 6). Não existe intervalo considerado normal. Não houve diferenças estatisticamente significantes entre os grupos ou entre as medidas iniciais e finais $(p=0,507)$.

Os valores do parâmetro $G$, que reflete a firmeza do coágulo (G), em d/sc, nos grupos G1, G2 e G3 iniciais foram 6336,45 \pm $2593,49,5412,25 \pm 1101,19$ e $6168,53 \pm 1697,71$ e os valores finais foram $6637,82 \pm 1844,56,4847,30 \pm 893,72$ e 6053,83 $\pm 1609,83$, respectivamente (Figura 7 ). O intervalo de refe-

Revista Brasileira de Anestesiologia Vol. 53, N 6, Novembro - Dezembro, 2003 
rência para este parâmetro é de 4433 a 6904 d/sc. Em todos os traçados os valores de $\mathrm{G}$ encontravam-se dentro do intervalo considerado normal. Não houve diferenças estatisticamente significantes entre os grupos ou entre as medidas iniciais e finais $(p=0,332)$.

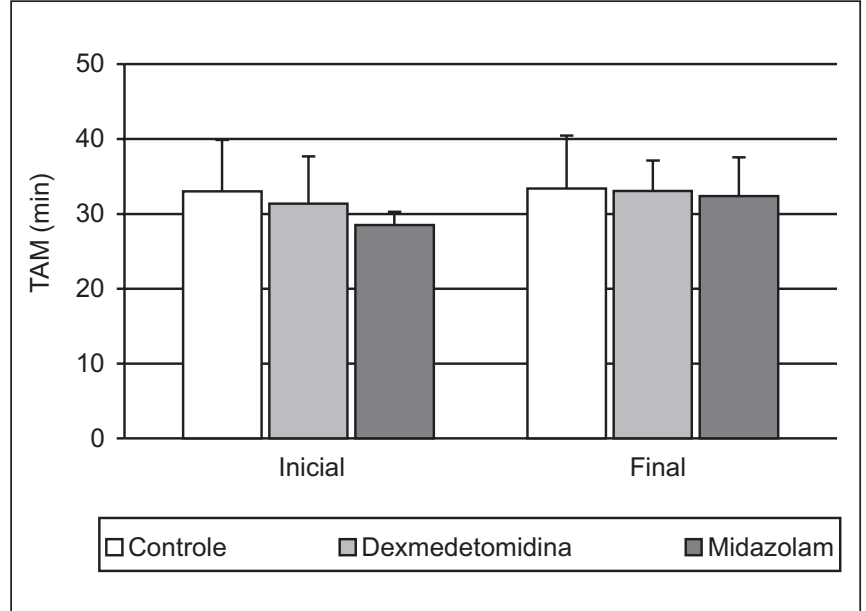

Figura 6 - Valores Iniciais e Finais do Tempo para Atingir a Amplitude Máxima (TAM)

Não houve diferenças estatisticamente significantes

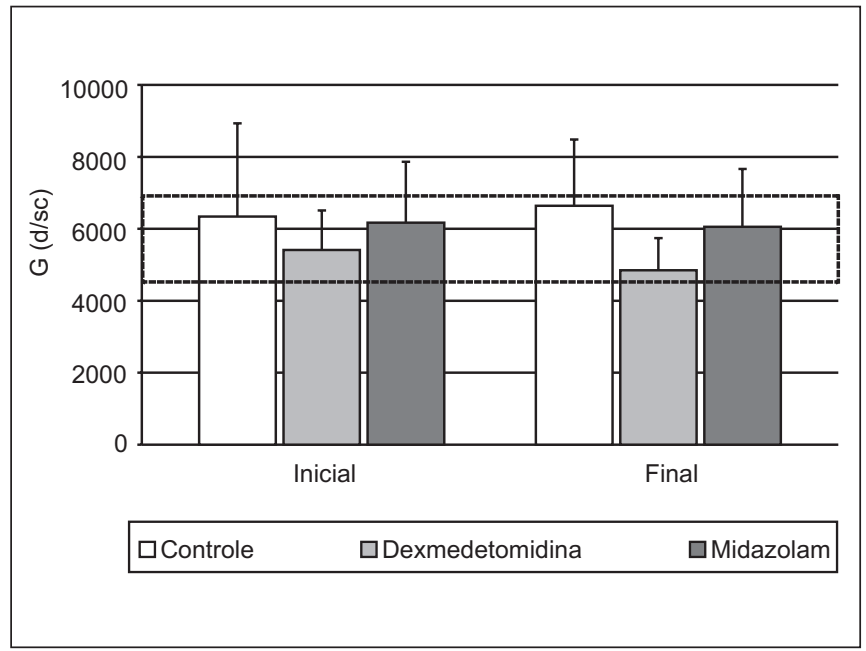

Figura 7 - Valores Iniciais e Finais do Parâmetro de Firmeza do Coágulo (parâmetro G)

Entre as linhas tracejadas encontram-se os valores de referência. Não houve diferenças estatisticamente significantes

Os valores da lise percentual estimada do coágulo 30 minutos após atingida a AM (LPE), em porcentagem, nos grupos G1, G2 e G3 iniciais foram 2,62 $\pm 6,62,1,81 \pm 2,25$ e 2,93 \pm 1,89 e os valores finais foram $4,37 \pm 6,82,1,25 \pm 1,03$ e $1,31 \pm$ 1,27 , respectivamente (Figura 8 ). Não existe intervalo considerado normal. Não houve diferenças estatisticamente significantes entre os grupos ou entre as medidas iniciais e finais $(p=0,650)$.

Revista Brasileira de Anestesiologia

Vol. 53, № 6, Novembro - Dezembro, 2003

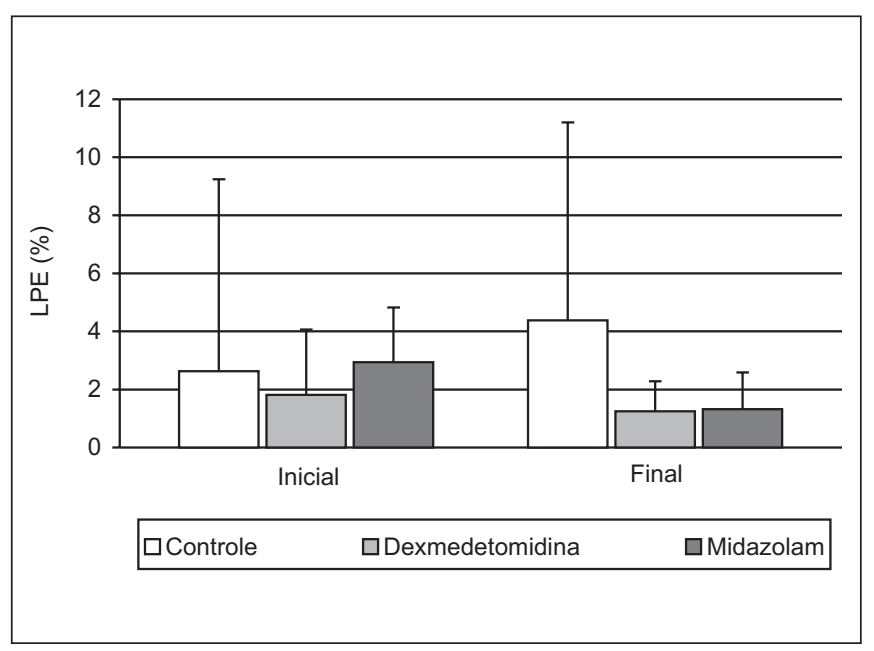

Figura 8 - Valores Iniciais e Finais da Lise Percentual Estimada após 30 minutos de atingida a AM (LPE)

Não existem valores de referência para este parâmetro. Não houve diferenças estatisticamente significantes

Os valores do índice de lise de coágulo de sangue total $30 \mathrm{mi}-$ nutos após atingida a AM (CL30), em porcentagem, nos grupos G1, G2 e G3 iniciais foram 93,01 $\pm 11,83,93,83 \pm 5,85$ e $93,97 \pm 2,51$ e os valores finais foram $90,63 \pm 11,38,95,61 \pm$ 2,61 e $96,46 \pm 2,32$, respectivamente (Figura 9). Não existe intervalo considerado normal. Não houve diferenças estatisticamente significantes entre os grupos ou entre as medidas iniciais e finais $(p=0,683)$.

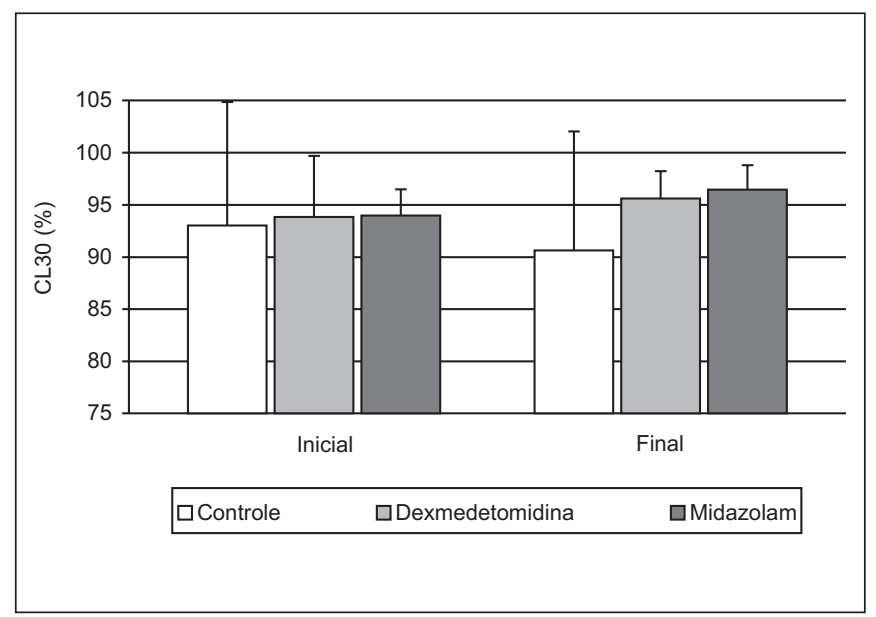

Figura 9 - Valores Iniciais e Finais da Lise de Coágulo de Sangue Total após 30 minutos de atingida a AM (CL30) Não existem valores de referência para este parâmetro Não houve diferenças estatisticamente significantes

Os valores do índice de coagulação (IC) nos grupos G1, G2 e G3 iniciais foram $-0,08 \pm 1,81,-0,20 \pm 1,35$ e $0,02 \pm 1,56$ e os valores finais foram $0,52 \pm 1,14,-1,23 \pm 1,15$ e $-0,34 \pm 1,64$, respectivamente (Figura 10). O intervalo de referência para este parâmetro é de $+3,0$ a -3,0. Em todos os traçados, os valores do IC encontravam-se dentro do intervalo considerado 
normal. Não houve diferenças estatisticamente significantes entre os grupos, quando estes foram analisados conjuntamente através de análise de variância $(p=0,304)$; porém, quando se comparou as medidas iniciais e finais dos grupos separadamente, a dexmedetomidina diminuiu o valor do IC de forma estatisticamente significativa $(p=0,026)$.

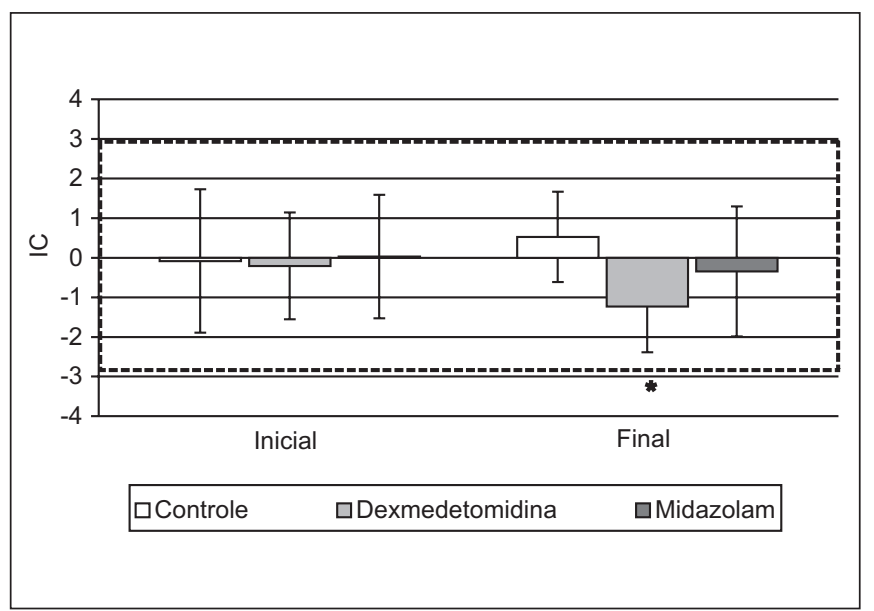

Figura 10 - Valores Iniciais e Finais do Índice de Coagulação (IC) Entre as linhas tracejadas encontram-se os valores de referência

* $p \leq 0,05$ em relação ao grupo dexmedetomidina inicial

A figura 11 mostra as curvas de tromboelastografia traçadas a partir das médias dos valores dos diferentes parâmetros, agrupadas aos pares (inicial em linha contínua e final em linha tracejada), obtidas dos 24 pacientes incluídos neste estudo.

\section{DISCUSSÃO}

Os adrenoceptores $\alpha_{2}$ são receptores transmembrana com porções hidrofóbicas e hidrofílicas que reagem seletivamente com ligantes extracelulares (hormônios endógenos e molecular exógenas, como drogas) para iniciar uma cascata de eventos que levam a um efeito fisiológico mediado pelo acoplamento destes receptores com a proteína $\mathrm{G}^{17}$. Vários mecanismos efetores já foram descritos, decorrentes do estímulo destes receptores, incluindo entre eles a inibição da enzima adenilciclase ${ }^{18}$, hiperpolarização celular pela abertura de canais de potássio $\left(\mathrm{K}^{+}\right)^{19,20}$, inibição da translocação de cálcio $\left(\mathrm{Ca}^{2+}\right)^{21}$ e da fosfolipase $\mathrm{C}$ e estímulo da fosfolipase $\mathrm{A}_{2}$ ${ }^{22}$. Estes receptores apresentam três subclasses, denominadas adrenoceptores $\alpha_{2 A}, \alpha_{2 B}$ e $\alpha_{2 C}$, cada um responsável por efeitos fisiológicos diferentes ${ }^{23}$. Estão distribuídos em diversos locais do organismo. O uso de agonistas de adrenoceptores $\alpha_{2}$ em anestesia deve-se à estimulação destes receptores no locus cœruleus, mediando os efeitos sedativos, e no corno dorsal da medula, resultando em analgesia ${ }^{4,24,25}$. Outros efeitos desejáveis em anestesia são os efeitos cardiovasculares, decorrentes da diminuição do tônus simpático ${ }^{26}$.

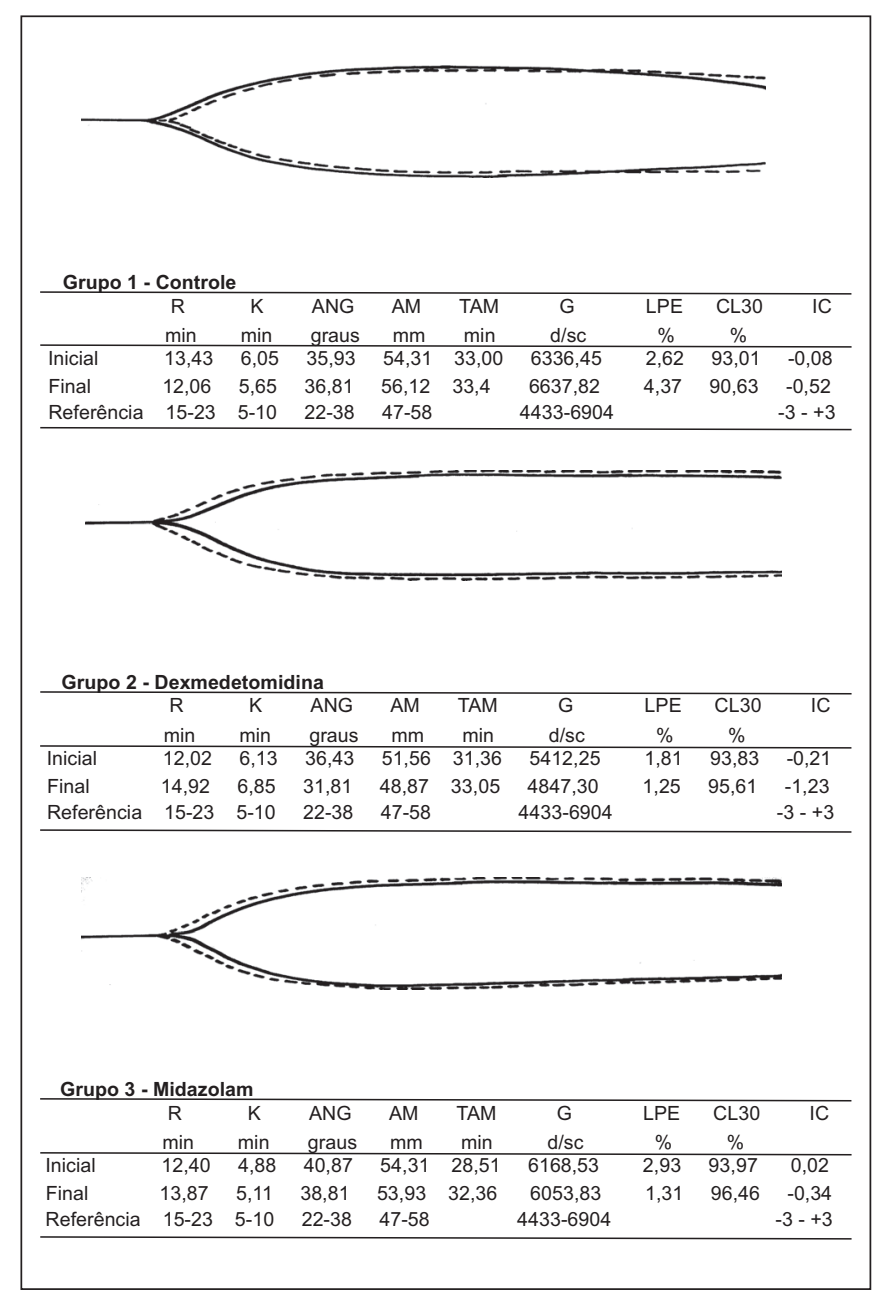

Figura 11 - Curvas de Tromboelastografia Traçadas a Partir das Médias dos Valores dos Diferentes Parâmetros, Agrupadas aos Pares (inicial em linha tracejada e final em linha contínua), Obtidas dos 24 Pacientes Incluídos neste Estudo

A dexmedetomidina é um agonista dos adrenoceptores $\alpha_{2}$, com seletividade $\alpha_{1} / \alpha_{2}$ de $1 / 1600$, e age sobre as três subclasses de adrenoceptores $\alpha_{2}{ }^{27}$.

A estimulação dos adrenoceptores $\alpha_{2}$ pode interferir sobre a coagulação sangüínea por mecanismos diferentes, basicamente sobre o fenômeno de agregação plaquetária, por mecanismos diretos e indiretos.

Nas plaquetas, a agregação se dá sob estímulo dos adrenoceptores $\alpha_{2 \mathrm{~A}}$, por agonistas como a adrenalina ou a dexmedetomidina, via proteína $\mathrm{G}_{\mathrm{i}}$, levando à inibição da formação de 3'-5'- adenosina monofosfato cíclico (AMPc), com conseqüente acúmulo de adenosina difosfato $(A D P)^{28}$. O ADP causa inicialmente a liberação de íons $\mathrm{Ca}^{2+}$ ligados a fosfoproteínas, ativação de uma enzima ATPase dependente de $\mathrm{Ca}^{2+} \mathrm{e}$ ativação de actomiosina plaquetária (trombostenina), proteína contrátil. Esta reação leva a uma contração da plaqueta com mudança de sua conformação e modificação da estrutura de sua membrana ${ }^{29}$.

A ativação de adrenoceptores $\alpha_{2 A}$ pode também acelerar a troca de íons sódio por hidrogênio, levando a uma alcaliniza-

Revista Brasileira de Anestesiologia Vol. 53, N 6, Novembro - Dezembro, 2003 
ção do interior das plaquetas e estimulando o aumento da atividade da fosfolipase $A_{2}$, o que resulta em aumento da formação de tromboxano $\mathrm{A}_{2}{ }^{22}$. O tromboxano $\mathrm{A}_{2}$ é um poderoso agente agregante e liberador dos conteúdos dos grânulos das plaquetas (serotonina, ADP), que perpetuam o fenômeno de agregação ${ }^{29}$.

A adrenalina é o principal agonista de adrenoceptores $\alpha_{2}$, responsável por estes efeitos pró-agregantes in vivo ${ }^{30}$. No entanto, sua ação hemostática é complementada por efeitos sobre adrenoceptores $\alpha_{1}$, responsáveis por parte da fase parietal da hemostasia, a vasoconstrição. Por outro lado, o estímulo puro de adrenoceptores $\alpha_{2}$ pode, através de dois mecanismos, apresentar efeito antiagregante: inibição da liberação de catecolaminas pelos terminais simpáticos ${ }^{14}$ e liberação de óxido nítrico (NO) ${ }^{31}$.

A estimulação dos adrenoceptores $\alpha_{2}$ localizados na membrana pré-sináptica do terminal simpático estimula a Na-K-ATPase, que resulta em diminuição de $\mathrm{Na}^{+}$intracelular e, conseqüentemente, diminuição da troca de $\mathrm{Na}^{+}$intracelular por $\mathrm{Ca}^{2+}$ extracelular. Esta queda da concentração de $\mathrm{Ca}^{2+}$ no interior do terminal nervoso resulta em diminuição da liberação das catecolaminas, e portanto em diminuição do tônus do sistema nervoso simpático ${ }^{11}$.

Também contribui para a anti-agregação a liberação de NO mediada pela estimulação de adrenoceptores $\alpha_{2}$ pelo endotélio vascular ${ }^{31,32}$. O NO age através de um complexo mecanismo que resulta em aumento dos níveis de AMPc intracelular. A fosforilação de uma proteína cinase dependente de $\mathrm{AMPc}$ conduz à remoção de $\mathrm{Ca}^{2+}$ do citoplasma das plaquetas para o seu local de estocagem e resulta no relaxamento das proteínas contráteis. A plaqueta volta à sua forma discóide e sua membrana, novamente sob tensão, perde sua afinidade por outras membranas, dando-se a desagregação ${ }^{29}$.

Estudo in vitro demonstrou que a dexmedetomidina é quase tão efetiva quanto a adrenalina em induzir agregação plaquetária ${ }^{13}$. Outro estudo, também in vitro, demonstrou que o NO é capaz de desagregar as plaquetas previamente agregadas por agonistas de adrenoceptores $\alpha_{2}{ }^{31}$.

Não existem na literatura trabalhos que avaliem o efeito conjunto dos fatores pró-agregantes e antiagregantes decorrentes da estimulação destes receptores. Além do efeito direto da dexmedetomidina em diminuir o tono simpático através da inibição da liberação de catecolaminas via adrenoceptores $\alpha_{2}$-pré-sinápticos, ela pode, à semelhança de outros agentes sedativos, diminuir o tono simpático de forma indireta, simplesmente pela ansiólise decorrente dos efeitos sobre o sistema nervoso central. Um estudo ${ }^{14}$ demonstrou a diminuição das concentrações plasmáticas de noradrenalina e cortisol em pacientes que receberam tiopental, propofol e midazolam. Estudos em animais também demonstraram a diminuição dos níveis plasmáticos de catecolaminas após administração de doses sedativas de midazolam ${ }^{33,34}$.

Ainserção do grupo G3 (midazolam) no presente estudo teve o intuito de diferenciar-se o efeito da dexmedetomidina sobre a coagulação decorrente dos mecanismos diretos e/ou indiretos promovidos por este fármaco.
Existem vários métodos para se acessar a função hemostática em humanos. Todos os métodos apresentam vantagens e desvantagens. Para o presente estudo escolheu-se a tromboelastografia (TEG) ${ }^{16}$.

ATEG permite uma avaliação completa da formação do coágulo e as características estruturais e estabilidade do coágulo formado. Os testes de laboratório rotineiramente empregados são realizados em frações de plasma centrifugado e examinam etapas isoladas do processo de coagulação. Arecente compreensão dos complexos de enzimas que existem na superfície das células envolvidas no processo de coagulação e a transferência de substâncias até a formação da fibrina levou à discussão sobre a utilidade de testes convencionais como o Tempo de Protrombina (TP) e Tempo de Tromboplastina Parcial Ativada (TTPA), nos quais a superfície celular das plaquetas (local onde estes fenômenos ocorrem) é substituída por outros fatores de contato. ATEG utiliza a própria superfície das plaquetas para avaliar a formação do coágulo, sendo portanto sensível à função plaquetária, fatores plasmáticos e ativadores e inibidores da coagulação.

Este método já foi utilizado para avaliação do efeito do propofol sobre a coagulação, porém as amostras eram incubadas in vitro ${ }^{35}$. No presente estudo, a dexmedetomidina e o midazolam foram administrados aos pacientes e seus efeitos avaliados após 30 minutos, tempo suficiente para exercerem suas atividades diretas e indiretas, discutidas previamente. Dessa forma pode-se avaliar os efeitos da dexmedetomidina não apenas sobre os adrenoceptores $\alpha_{2 A}$ plaquetários, mas também seus efeitos sobre a liberação do óxido nítrico e a diminuição do tônus simpático que ocorrem in vivo.

Em nosso estudo, nem a dexmedetomidina e nem o midazolam alteraram os parâmetros da tromboelastografia mais sensíveis às alterações plaquetárias (Amplitude Máxima AM e Tempo de Formação do Coágulo - K).

O Tempo de Reação encontrado nos três grupos, tanto nos traçados iniciais quanto nos finais, apresentava-se abaixo do valor considerado normal. Uma possível explicação para este fato seria o retardo de 1 minuto no início de processamento da amostra, já que se este tempo for considerado, os valores de $R$ aproximam-se da faixa de normalidade. No grupo que recebeu dexmedetomidina, a maioria dos pacientes apresentou curva final com padrão de menor coagulabilidade em relação à curva inicial; porém apenas o Tempo de Reação $(R)$ foi estatisticamente diferente, sem alcançar, entretanto, o limite inferior do intervalo de referência. A diferença encontrada é clinicamente irrelevante. O mesmo raciocínio aplica-se na avaliação do Índice de Coagulação (IC) que foi menor em relação ao seu próprio controle, com diferença estatisticamente significante. O Índice de Coagulação reflete a coagulação global e é o resultado da interação de todos os parâmetros da fase de formação do trombo medidos pela tromboelastografia. Esta diferença limita-se à estatística, uma vez que tanto os parâmetros iniciais quanto os finais encontravam-se dentro dos valores de referência. Logo, a interação dos mecanismos pró e antiagregantes da dexmedetomidina foi capaz de alterar os traçados no sentido da hipocoagulação; porém, os traçados finais mantiveram-se dentro da 
normalidade, exprimindo que, mesmo afetando a coagulação, a dexmedetomidina não aumentaria o risco de sangramento. O grupo que recebeu midazolam não se comportou desta maneira, sugerindo que o resultado obtido no grupo que recebeu dexmedetomidina deve-se primariamente aos seus efeitos diretos, uma vez que a dexmedetomidina e o midazolam compartilham dos mesmos efeitos indiretos sobre a coagulação.

O paciente do G2 que recebeu uma dose de manutenção maior de dexmedetomidina ( $25 \%$ maior que o programado), bem como o paciente do G3 que recebeu dose complementar de midazolam (30\% maior que a dose inicial), não apresentaram comportamento, com relação à coagulação, diferente dos demais pacientes.

Com relação à fase de fibrinólise, que se inicia após atingida a amplitude máxima, os parâmetros estudados são de difícil interpretação, pois não há valores de referência associados aos parâmetros Lise Percentual Estimada do Coágulo (LPE) e Lise de Coágulo de Sangue Total (CL30). Na prática clínica, considera-se o comportamento das curvas seqüenciais para a interpretação destes dados. Partindo de uma mesma linha de base, os grupos que receberam dexmedetomidina ou midazolam apresentaram menor lise do coágulo após 30 minutos, ao contrário do grupo controle, em que a lise do coágulo aumentou após 30 minutos. No entanto, a diferença entre os valores pré e pós de LPE e CL30 não se mostraram estatisticamente significantes. Um paciente no grupo controle foi responsável pelo grande desvio padrão apresentado por este grupo nos parâmetros que concernem à fibrinólise. Entretanto, excluindo-se este paciente e refazendo-se os cálculos estatísticos, os três grupos continuaram a não se mostrar estatisticamente diferentes.

Do presente estudo, concluímos que, após 30 minutos de infusão contínua, o efeito anticoagulante da dexmedetomidina prevaleceu sobre o efeito pró-coagulante. Este efeito apresenta diferença estatística; porém, sem impacto clínico, uma vez que os valores obtidos nos traçados após a infusão desta droga mantiveram-se dentro dos intervalos considerados normais. Este efeito parece ser decorrente dos efeitos diretos da dexmedetomidina e não dos efeitos indiretos (sedação e ansiólise), já que os pacientes do grupo dexmedetomidina apresentaram comportamento diferente daqueles que receberam midazolam, e estes, comportamento semelhante aos que receberam apenas solução fisiológica.

Com relação à fase de fibrinólise, houve uma tendência dos grupos dexmedetomidina e midazolam em diminuí-la após 30 minutos em relação ao grupo controle; porém, de forma estatística e clinicamente não significantes.

\section{Effects of Dexmedetomidine on Blood Coagulation Evaluated by Thromboelas- tography}

César Romão Martins, M.D.; Maria Angela Tardelli, TSA, M.D.; José Luiz Gomes do Amaral, TSA, M.D.

\section{INTRODUCTION}

Dexmedetomidine is a sympathomimetic agent with $1 / 1600$ selectivity for $\alpha_{2}$-adrenoreceptors as compared to $\alpha_{1}$ receptors. This selective action gives this drug hypnotic properties through $\alpha_{2}$-receptors stimulation in locus coerulleus, and analgesic properties through these receptors stimulation in spinal cord dorsal horn ${ }^{1-5}$.

These properties, allied to hemodynamic stability and minor respiratory depression, have rendered dexmedetomidine an interesting option for Intensive Care sedation ${ }^{6}$.

Dexmedetomidine has also been used in anesthesia for a wide variety of procedures. There are reports on dexmedetomidine providing sedation in procedures under local anesthesia, and even as adjuvant in major surgical procedures ${ }^{7,8}$. The potential benefit of dexmedetomidine during anesthesia is evidenced by decreased intraoperative hypnoanalgesics consumption by potentiating their action, thus decreasing side-effects, especially ventilatory, cardiovascular and depressing effects ${ }^{9-12}$.

It is known that $\alpha_{2}$-adrenoreceptors stimulation by epinephrine or dexmedetomidine may, in vitro, induce platelet aggregation ${ }^{13}$. In vivo, however, dexmedetomidine promotes nitric oxide (NO) release in vascular endothelium ${ }^{4}$ and decreases catecholamine release thru negative feedback by $\alpha_{2}$ pre-synaptic adrenoreceptors stimulation ${ }^{14}$, resulting in anti-platelet aggregation effect ${ }^{4}$. The use of hypnotics to promote anxiolysis and sedation during anesthesia could also interfere with the coagulation process by decreasing sympathetic activity ${ }^{15}$. The final effect of the interaction of those factors on coagulation has still not been shown.

Thromboelastography is a method which allows homeostatic function evaluation as from a small blood sample, documenting the interaction between platelets and coagulation cascade proteins, since the initial platelets and fibrin interaction, going through platelet aggregation, clot retraction and lysis. Curves generated by these interactions inform about coagulation factors activity, platelet function and fibrinolytic process ${ }^{16}$.

The purpose of this study was to evaluate dexmedetomidine's effects on blood coagulation through thromboelastography and to determine whether its effects on coagulation are mediated by direct or indirect mechanisms.

\section{METHODS}

After the Research Ethics Committee, Universidade Federal de São Paulo - Escola Paulista de Medicina, approval, 24 patients of both genders, aged 18 to 45 years, candidate to sur- 
gical procedures in which dexmedetomidine or midazolam could possibly be used in the beginning of the procedure gave their informed consent and were included in this study.

Exclusion criteria were body mass equal to or below 30 $\mathrm{kg} \cdot \mathrm{m}^{-2}$, known or suspected history of coagulation problems, use of drugs interfering with coagulation (AAS, NSAIDs, Ginko biloba, oral anticoagulants, heparin or heparin-derived drugs) and patients hydrated in the immediate preoperative period with Ringer's or colloid solutions, or those having received blood byproducts. Patients with diseases which may course with coagulation changes, such as neoplasias, major tissue injuries and platelet-deficient patients or those with preoperative coagulogram abnormalities were also excluded from the study.

Patients were randomly distributed in 3 groups, according to sedation protocol: $\mathrm{G} 1$, control - saline solution $(0.9 \% \mathrm{NaCl})$; G2 - dexmedetomidine; and G3 - midazolam.

All patients were monitored with two-lead cardioscope, pulse oximetry and non-invasive blood pressure at operating room arrival. A venous access was obtained in one upper limb with $20 \mathrm{G}$ catheter and hydration was started with $4 \mathrm{ml} . \mathrm{kg}^{-1} \cdot \mathrm{h}^{-1} \mathrm{sa}-$ line solution $(0.9 \% \mathrm{NaCl})$. Another vein was then punctured for $2 \mathrm{ml}$ blood sampling for control thromboelastography. After that, G1 patients were maintained with saline only, G2 patients received $1 \mu \mathrm{g} . \mathrm{kg}^{-1}$ dexmedetomidine in 10 minutes, followed by $0.4 \mu \mathrm{g} \cdot \mathrm{kg}^{-1} \cdot \mathrm{h}^{-1}$ maintenance dose and $\mathrm{G} 3$ patients received $0.05 \mathrm{mg} \mathrm{kg}^{-1}$ intravenous midazolam. The objective of sedation was to maintain patients within scores 3 or 4 of Ramsay's sedation scale (sleeping by awakened when called or at mild glabella compression). Second blood sampling (2 $\mathrm{ml}$ ) for thromboelastography was collected 30 minutes after saline infusion for $\mathrm{G} 1$, dexmedetomidine for $\mathrm{G} 2$ and midazolam for $\mathrm{G} 3$.

Thromboelastography: blood samples were collected after upper limb tourniquet and disinfection with $70 \%$ alcohol with $30 \times 7$ needle and $3 \mathrm{ml}$ syringe, in a total of $2 \mathrm{ml}$. Achronometer was immediately triggered and samples were packed in dry silicone-coated vials and taken to the thromboelastography machine (Thromboelastograph Coagulation Analyzer ${ }^{\circledR}$ Model 5000 - Haemoscope Corporation). Samples of $360 \mu \mathrm{l}$ were pipetted and placed in machine containers. Containers were positioned for beginning of test and the computer was activated always 1 minute after collection. Patients with any change in control thromboelastrography curves, as well as with dexmedetomidine or midazolam-mediated adverse reactions would be excluded from the protocol.

After second sampling collection, patients were released from the protocol and could receive any anesthetic scheme, at the sole judgment of the anesthesiologist in charge.

Thromboelastographic curve evaluated parameters were (Figure 1):

1. Reaction time (parameter R): time elapsed from the beginning of sample processing to TEG diagram to reach 2 $\mathrm{mm}$. This is the farthest point most traditional coagulation tests reach. It represents initial fibrin formation time and is functionally related to plasma coagulation factors and anticoagulant circulating factors activity. It may increase in situations of coagulation factors deficiency, anti-coagulation (heparin) or severe hypofibrinogenemia. A short $\mathrm{R}$ is related to hypercoagulation states;

2. Clot formation time (parameter $\mathrm{K}$ ): time from beginning of clot formation ( $R$ ) until $20 \mathrm{~mm}$ curve amplitude. $\mathrm{K}$ is a clot kinetic measure. It may be decreased by fibrinogen increase and, in a lesser degree, by platelet function. It may be increased by anticoagulants affecting both factors;

3. $\alpha$ angle $\left(\alpha^{\circ}\right)$ : the angle formed by TEG curve from R to K. It expresses the speed with which a solid clot is formed. It is decreased in the presence of hypofibrinogenemia and platelet hypofunction;

4. Maximum amplitude (MA): highest amplitude reached by TEG curve. It reflects absolute firmness reached by the clot. It is the most sensitive parameter for qualitative or quantitative platelet disorders;

5. Time for Maximum Amplitude (TMA): reflects total clot formation kinetics or time to the formation of a stable clot;

6. Clot firmness (parameter $G$ ): sensitive to minor changes in clot resistance or division;

7. Total Blood Clot Lysis (CL30): measures curve amplitude 30 minutes after maximum amplitude is reached in relation to maximum amplitude;

8. Estimated Percentage Lysis (EPL): represents amplitude decrease in percentage 30 minutes after maximum amplitude is reached;

9. Coagulation index $(\mathrm{Cl})$ : describes general coagulation and is obtained through an equation of linear combinations of R, K, MA and $\alpha^{\circ}$ variables. It depicts the general scenario of all clot formation factors interaction.

Student's $t$ test with Bonferroni's correction was used to analyze age and weight distributions. Fisher's proportion test was used for gender distribution. Analysis of Variance (ANOVA) was used to globally compare thromboelastography parameters and paired $T$ test was used to compare pre and post-treatment values for each group separately, considering significant $p<0.05$.

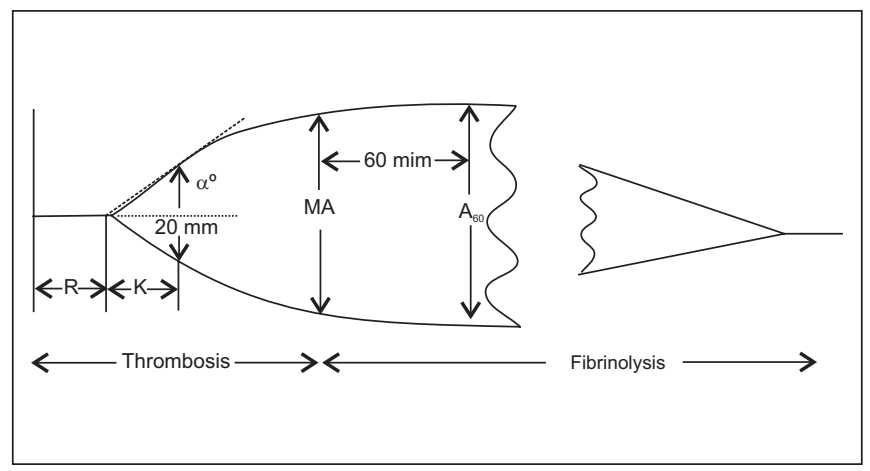

Figure 1 - Thromboelastography Variables Quantification. Curve Analysis ${ }^{13}$

$\mathrm{R}=$ Reaction Time $; \mathrm{K}=$ time for the curve to reach $20 \mathrm{~mm} ; \alpha^{\circ}=$ angle formed by the line uniting $\mathrm{R}$ to $\mathrm{K} ; \mathrm{MA}=$ Maximum Amplitude; $\mathrm{A}_{60}=$ Amplitude 60 minutes after reaching Maximum Amplitude 


\section{RESULTS}

There were no statistically significant differences in demographics data among groups (Table I).

Table I - Demographics Data

\begin{tabular}{lccc}
\hline & Control & Dexmedetomidine & Midazolam \\
\hline Weight $(\mathrm{kg}){ }^{*}$ & $64.5 \pm 8.62$ & $68.9 \pm 10.77$ & $65.6 \pm 9.12$ \\
Age (years) * & $34.125 \pm 5.462$ & $34.375 \pm 6.209$ & $34.875 \pm 8.983$ \\
Gender & & & \\
Female & 4 & 3 & 4 \\
Male & 4 & 5 & 4 \\
\hline
\end{tabular}

* Values expressed in Mean \pm SD

There were no statistically significant differences in groups' composition

Only one patient originally belonging to control group was excluded from the study for presenting initial thromboelastography curve with fibrinolysis patterns.

One G2 patient required dexmedetomidine maintenance dose increment to $0.5 \mu \mathrm{g} \cdot \mathrm{kg}^{-1} \cdot \mathrm{h}^{-1}$ and one $\mathrm{G} 3$ patient required additional $1 \mathrm{mg}$ midazolam to maintain scores 3 or 4 in Ramsay's sedation scale.

Initial reaction time values (parameter $\mathrm{R}$ ), in minutes, for $\mathrm{G} 1, \mathrm{G} 2$ and $\mathrm{G} 3$ were $13.43 \pm 3.13,12.02 \pm 4.21$ and $12.40 \pm$ 3.94. Final values were $12.06 \pm 1.99,14.92 \pm 2.43$ and 13.87 \pm 5.02 (Figure 2). Reference range for this parameter is 15 to 23 minutes. Initial and final $R$ values for all groups have remained below lower normal limit, but there have been no statistically significant differences between groups when compared together by analysis of variance $(p=0.537)$. When groups were separately studied and initial measures were compared to final measures, dexmedetomidine has significantly increased $R(p=0.03)$.

Initial time in minutes for the curve to reach $20 \mathrm{~mm}$ (parameter $\mathrm{K}$ ) for $\mathrm{G} 1, \mathrm{G} 2$ and $\mathrm{G} 3$ were $6.05 \pm 2.17,6.13 \pm 2.25$ and $4.88 \pm$ 1.54 , and final values were $5.65 \pm 1.33,6.85 \pm 1.62$ and $5.11 \pm$

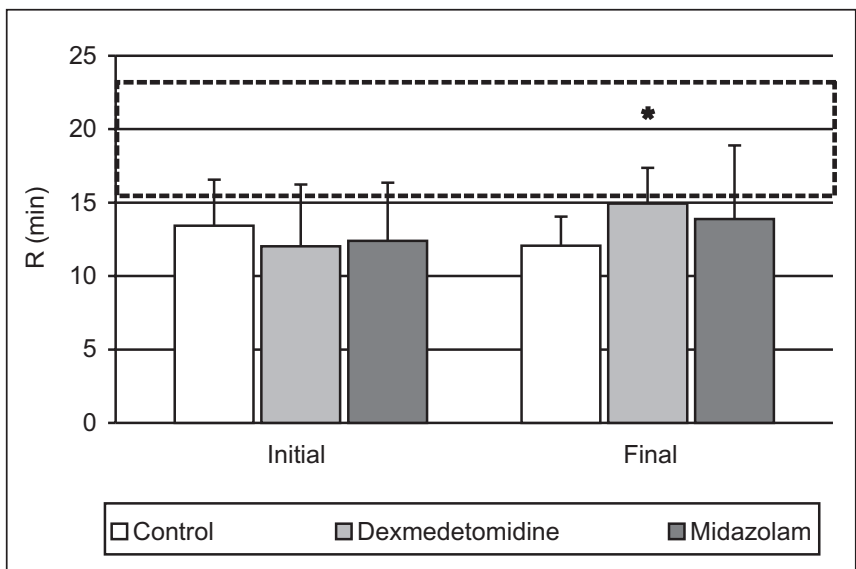

Figure 2 - Initial and Final Reaction Time Values (parameter R), in Minutes

Reference values are between dotted lines

${ }^{*} p \leq 0.05$ as compared to initial dexmedetomidine group
1.69 respectively (Figure 3 ). Reference range for this parameter is 5 to 10 minutes. Only initial group 3 (midazolam) curves had $\mathrm{K}$ values below lower limit $(4.88 \mathrm{~min})$. All other curves were within normal ranges, but close to lower limit. There were no statistically significant differences between groups or between initial and final measures within each group $(p=0.289)$.

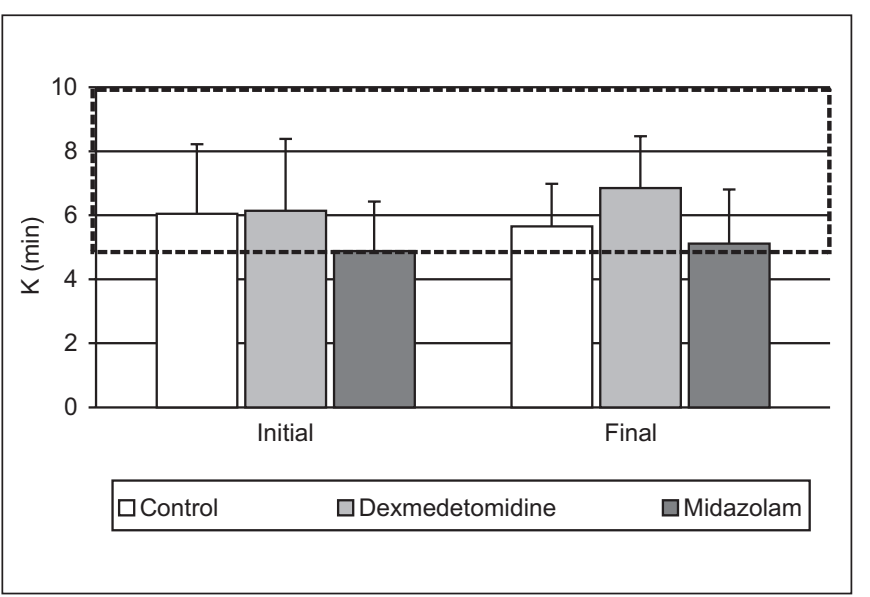

Figure 3 - Initial and Final Values of Time taken by Clot to reach 20 $\mathrm{mm}$ (parameter $\mathrm{K}$ or clot formation time), in minutes

Reference values are between dotted lines. There were no statistically significant differences

Initial $\alpha$ angle values, in degrees, in $\mathrm{G} 1, \mathrm{G} 2$ and $\mathrm{G} 3$ were $35.93 \pm 10.35,36.43 \pm 12.02$ and $40.87 \pm 8.66$, and final values were $36.81 \pm 8.55,31.81 \pm 7.01$ and $38.81 \pm 10.11$ respectively (Figure 4 ).

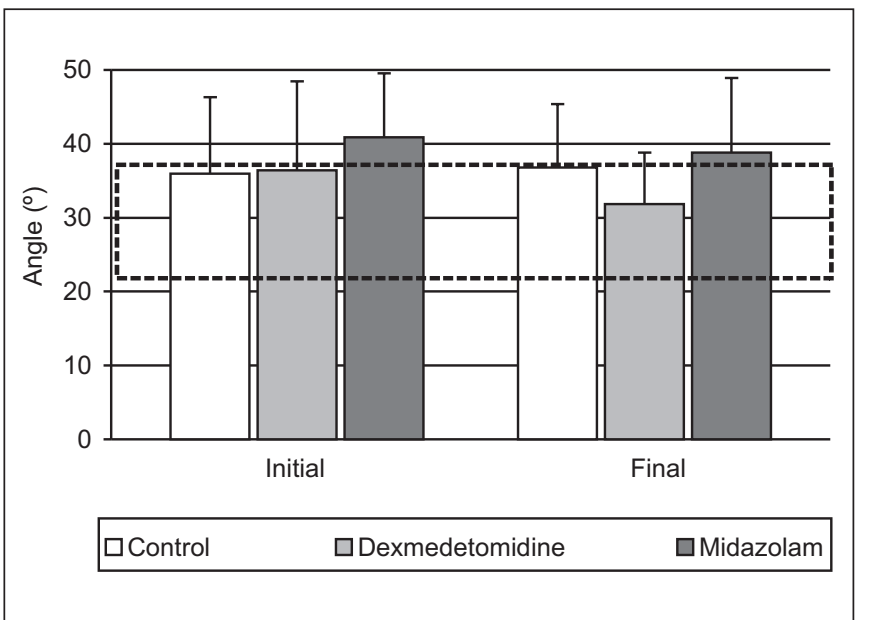

Figure 4 - Initial and Final Alpha angle $(\alpha)$ Values

Reference values are between dotted lines

There were no statistically significant differences

Reference range for this parameter is 22 to 38 degrees. In initial G3 (midazolam) curves, $\alpha$ angle values were above upper limit and have remained so in final curves. For other groups curves these values were within normal ranges, however close to upper limit. Once again, there were no statistically Vol. 53, N 6, Novembro - Dezembro, 2003 
significant differences between groups or between initial and final measures within each group $(p=0.551)$.

Initial maximum amplitude (MA) in millimeters for G1, G2 and G3 were $54.31 \pm 8.02,51.56 \pm 4.52$ and $54.31 \pm 6.95$, and final values were $56.12 \pm 6.64,48.87 \pm 4.41$ and $53.93 \pm 6.54$ respectively (Figure 5 ). Reference range for this parameter is 47 to $58 \mathrm{~mm}$. All curves have shown values within normal interval. There were no statistically significant differences between groups or between initial and final measures within each group $(p=0.274)$.

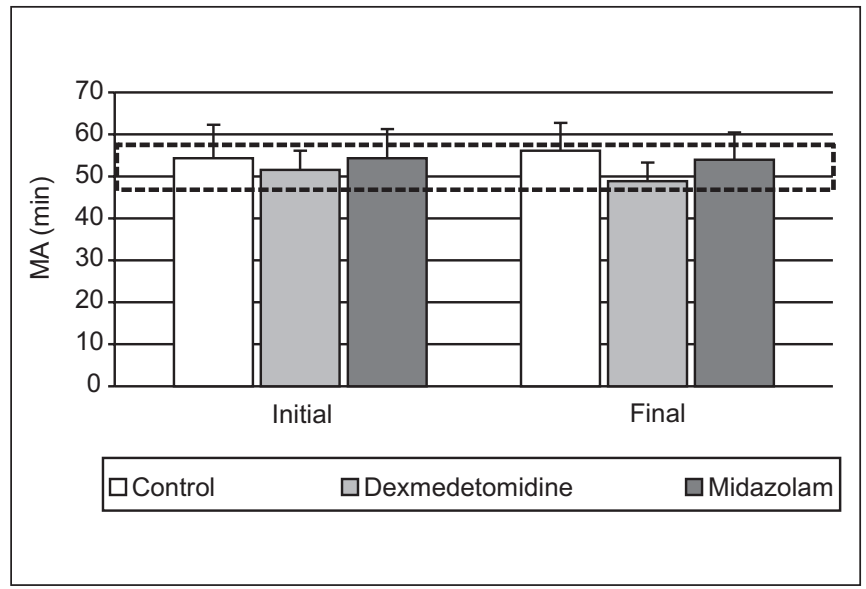

Figure 5 - Initial and Final Maximum Amplitude (MA) Time Reference values are between dotted lines. There were no statistically significant differences

Initial time for maximum amplitude values (TMA) in minutes for $\mathrm{G} 1, \mathrm{G} 2$ and $\mathrm{G} 3$ were $33.00 \pm 6.85,31.36 \pm 6.33$ and $28.51 \pm$ 1.77 , and final values were $33.4 \pm 7.06,33.05 \pm 4.09$ and $32.36 \pm 5.20$ respectively (Figure 6 ). There is no normal reference interval. There were no statistically significant differences between groups or between initial and final measures within each group $(p=0.507)$.

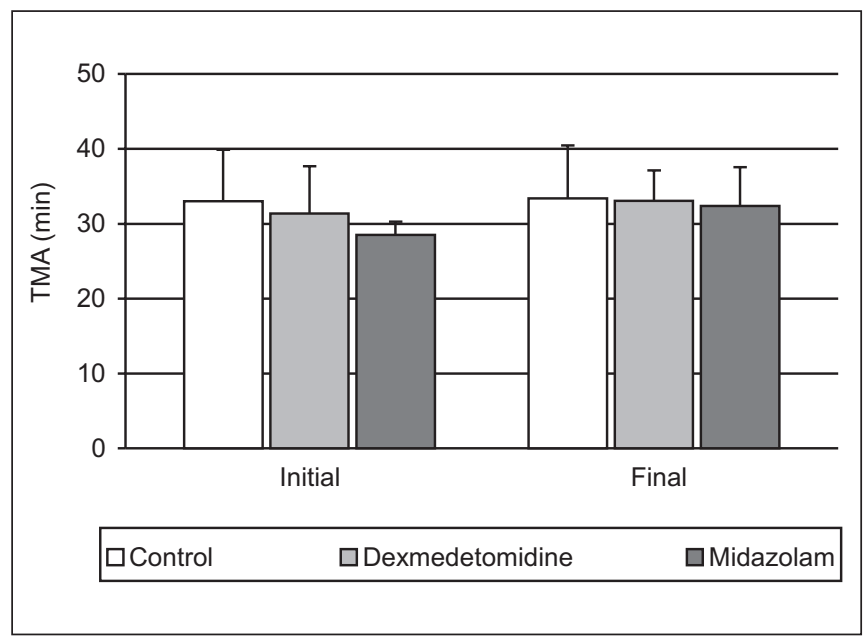

Figure 6 - Initial and Final Time to Reach Maximum Amplitude (TMA) values

There were no statistically significant differences

Revista Brasileira de Anestesiologia

Vol. 53, Nº 6, Novembro - Dezembro, 2003
Initial parameter $G$ values, reflecting clot firmness $(G)$ in d/sc for G1, G2 and G3 were 6336.45 $\pm 2593.49,5412.25 \pm$ 1101.19 and $6168.53 \pm 1697.71$, and final values were $6637.82 \pm 1844.56,4847.30 \pm 893.72$ and $6053.83 \pm 1609.83$ respectively (Figure 7). Reference range for this parameter is 4433 to $6904 \mathrm{~d} / \mathrm{sc}$. In all curves, G values were within normal interval. There were no statistically significant differences between groups or between initial and final measures within each group $(p=0.332)$.

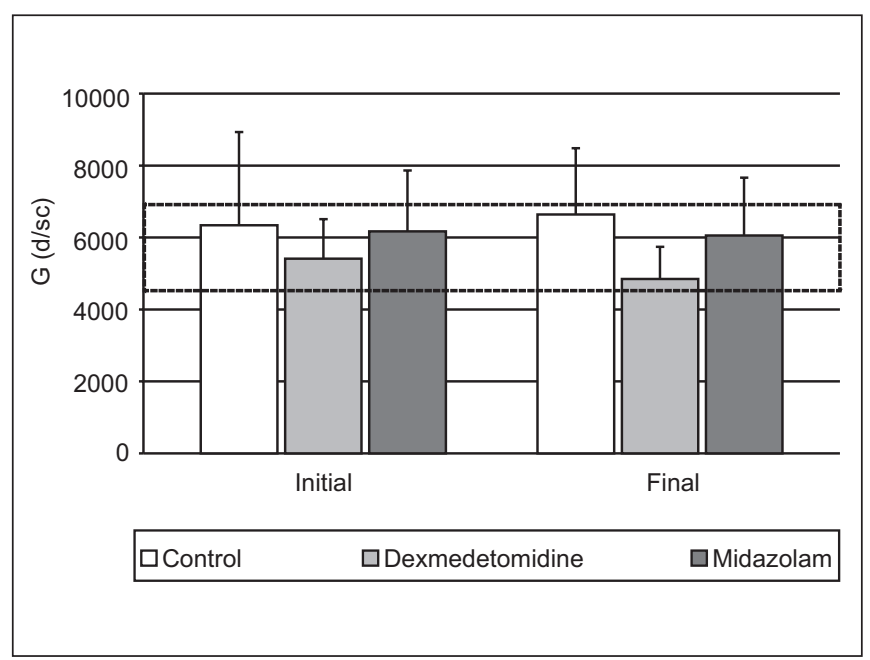

Figure 7 - Initial and Final Clot Firmness Parameter Values (parameter G)

Reference values are between dotted lines. There were no statistically significant differences

Initial estimated percentage clot lysis values 30 minutes after reaching $M A(E P L)$ for $G 1, G 2$ and $G 3$ were $2.62 \pm 6.62,1.81 \pm$ 2.25 and $2.93 \pm 1.89$, and final values were $4.37 \pm 6.82,1.25 \pm$ 1.03 e $1.31 \pm 1.27$ respectively (Figure 8 ). There is no normal reference interval. There were no statistically significant differences between groups or between initial and final measures within each group $(p=0.650)$.

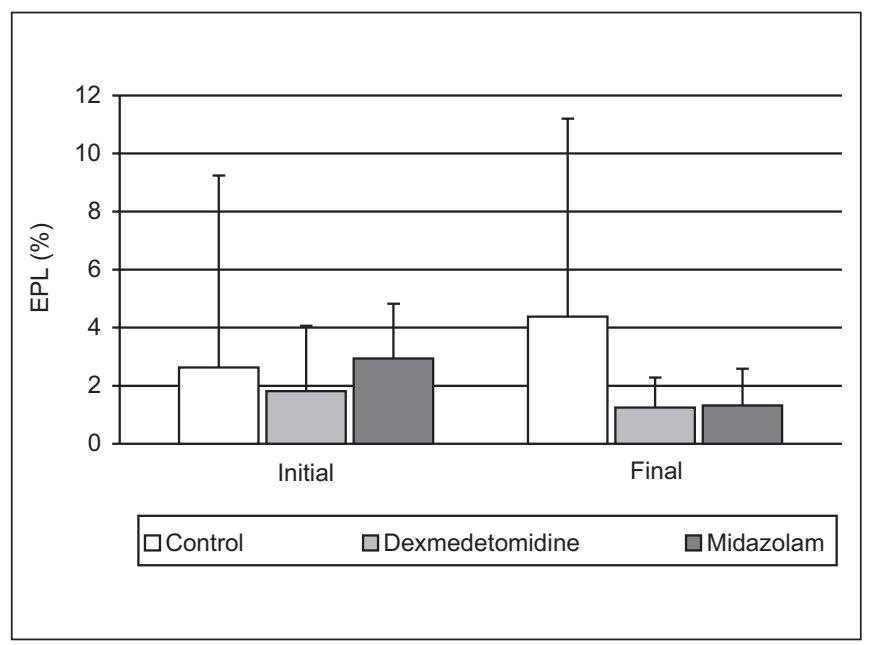

Figure 8 - Initial and Final Estimated Percentage Lysis Values 30 minutes after reaching $M A(E P L)$

There are no reference values for this parameter. There were no statistically significant differences 
Initial total blood lysis index values, in percentage, 30 minutes after reaching MA (CL30) for G1, G2 and G3 were $93.01 \pm$ $11.83,93.83 \pm 5.85$ and $93.97 \pm 2.51$, and final values were $90.63 \pm 11.38,95.61 \pm 2.61$ e $96.46 \pm 2.32$ respectively (Figure $9)$. There is no normal reference interval. There were no statistically significant differences between groups or between initial and final measures within each group $(p=0.683)$.

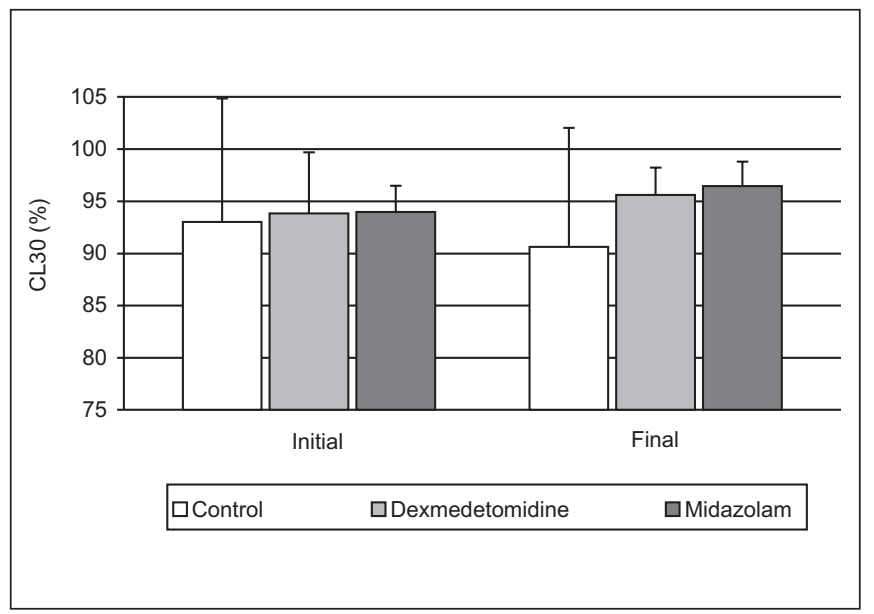

Figure 9 - Initial and Final Total Blood Clot Lysis 30 minutes after reaching MA (CL30)

There are no reference values for this parameter. There were no statistically significant differences

Initial coagulation index (CI) for G1, G2 and G3 were $-0,08 \pm$ $1.81,-0.20 \pm 1.35$ and $0.02 \pm 1.56$, and final values were 0.52 $\pm 1.14,-1.23 \pm 1.15$ e $-0.34 \pm 1.64$ respectively (Figure 10 ). Reference range for this parameter is +3.0 to -3.0 . In all curves, $\mathrm{Cl}$ values were within normal interval. There were no statistically significant differences between groups when analyzed together through analysis of variance $(p=0.304)$; however, when initial and final measures were separately compared for each group, dexmedetomidine has significantly decreased $\mathrm{Cl}$ value $(\mathrm{p}=0.026)$.

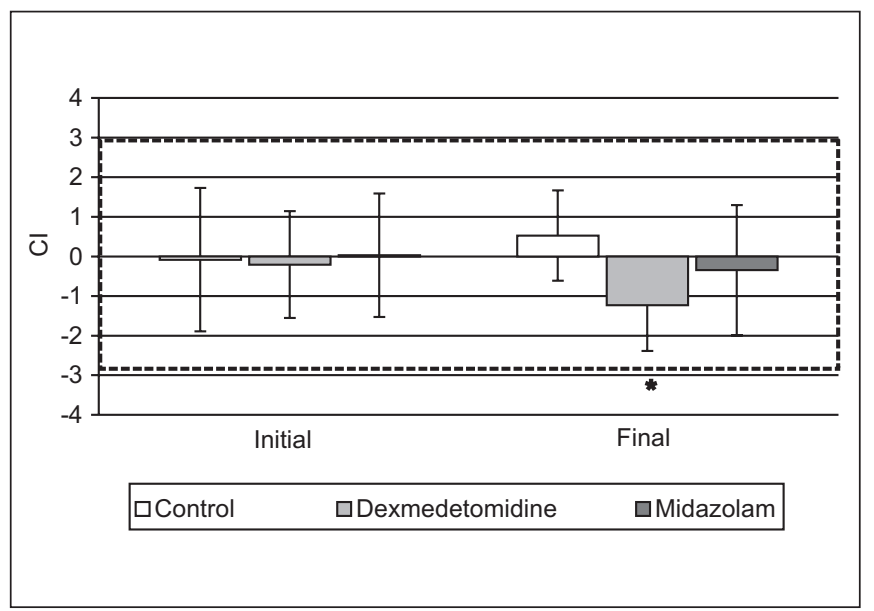

Figure 10 - Initial and Final Coagulation Index $(\mathrm{Cl})$ Values Reference values are between dotted lines

${ }^{*} p \leq 0.05$ as compared to initial dexmedetomidine group
Figure 11 shows thromboelastrography curves as from mean values of different parameters, grouped in pairs (initial in full line and final in dotted line), obtained from 24 patients included in this study.

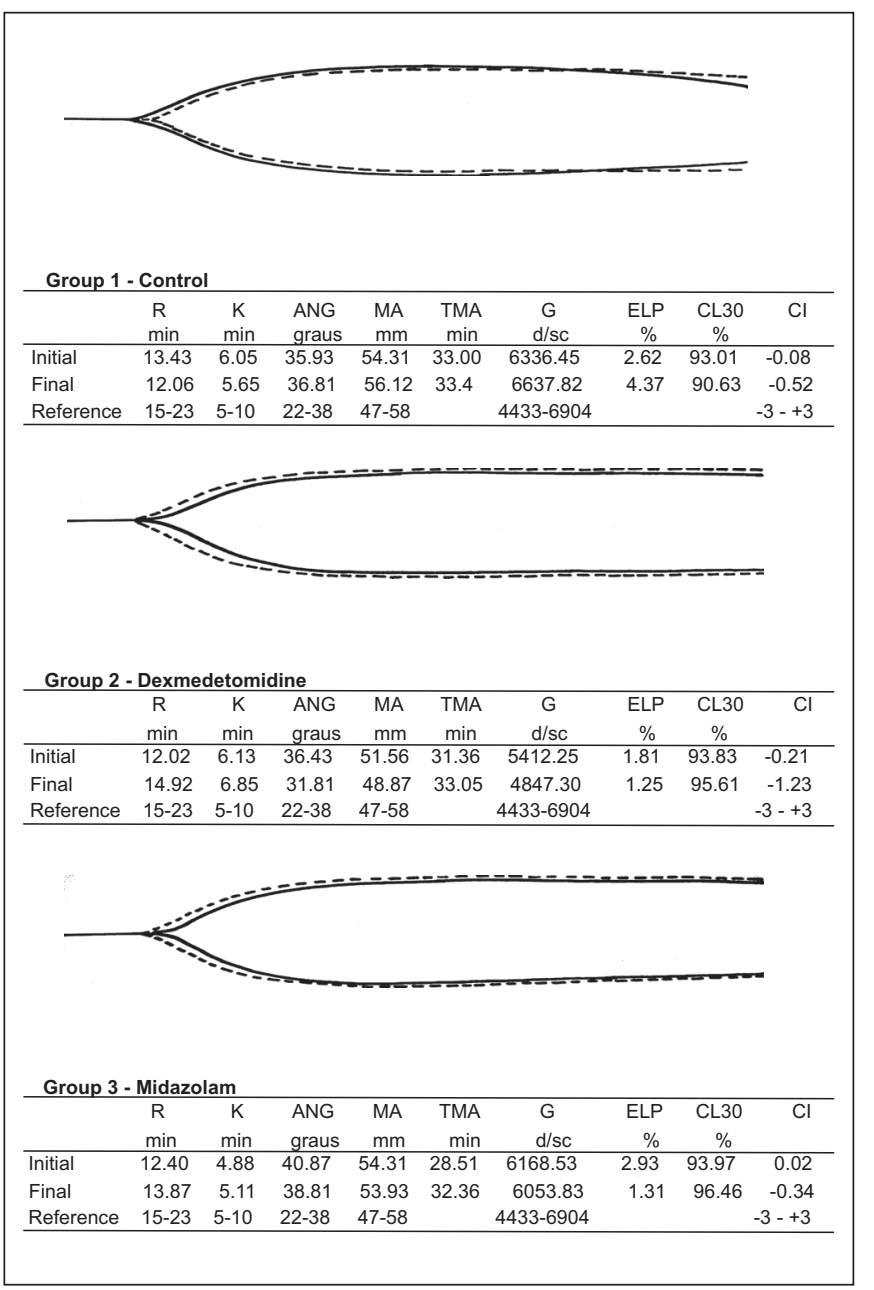

Figure 11 - Thromboelastography Curves Traced as from Mean Values of Different Parameters, Grouped in Pairs (initial in dotted line and final in full line), Obtained from the 24 Patients Included in this Study

\section{DISCUSSION}

Alpha $_{2}$-adrenoreceptors are transmembrane receptors with hydrophobic and hydrophilic portions which selectively react with extracellular ligants (endogenous hormones and exogenous molecules, such as drugs) to trigger a cascade of events leading to physiological effect mediated by the coupling of such receptors to $\mathrm{G}$ protein ${ }^{17}$. Several effector mechanisms have been described as a consequence of these receptors stimulation, like adenyl-cyclase enzyme inhibition $^{18}$, cell hyperpolarization by potassium channels opening $\left(\mathrm{K}^{+}\right)^{19,20}$, calcium $\left(\mathrm{Ca}^{2+}\right)$ and phospholipase $\mathrm{C}$ translocation inhibition ${ }^{21}$ and phospholipase $\mathrm{A}_{2}$ stimulation ${ }^{22}$. These receptors comprise three subclasses called $\alpha_{2 A}$, Vol. 53, № 6 , Novembro - Dezembro, 2003 
$\alpha_{2 B}$ and $\alpha_{2 C}$-adrenoreceptors, each one responsible for different physiological effects ${ }^{23}$. They are distributed in several body sites. Alpha ${ }_{2}$-adrenoreceptor agonists are used in anesthesia to stimulate such receptors in locus coerulleus, mediating sedative effects, and in spinal cord dorsal horn, resulting in analgesia ${ }^{4,24,25}$. Other desirable anesthetic effects are their cardiovascular actions, resulting from sympathetic tone decrease ${ }^{26}$.

Dexmedetomidine is an $\alpha_{2}$-adrenoreceptor agonist with $\alpha_{1} / \alpha_{2}$ selectivity of $1 / 1600$, which acts on all three $\alpha_{2}$-adrenoreceptor subclasses ${ }^{27}$.

Alpha $_{2}$-adrenoreceptors stimulation may interfere with blood coagulation through different mechanisms, but basically thru a direct and indirect platelet aggregation interference.

Platelet aggregation is a function of $\alpha_{2 A}$-adrenoreceptors stimulation by agonists such as epinephrine or dexmedetomidine, via protein $\mathrm{G}_{1}$, leading to the inhibition of cyclic 3'-5'-adenosine monophosphate (cAMP), with consequent adenosine diphosphate (ADP) build up ${ }^{28}$. ADP initially determines phosphoprotein-bound $\mathrm{Ca}^{2+}$ ions release, $\mathrm{Ca}^{2+}$-dependent ATP-ase enzyme activation and platelet actomyosine activation (thrombosthenin), a contractile protein. This reaction leads to platelet contraction with changes in conformation and membrane structure ${ }^{29}$.

Alpha $_{2 \mathrm{~A}}$-adrenoreceptors activation may also speed up sodium ions replacement by hydrogen, leading to internal platelet alkalinization and stimulating phospholipase $A_{2}$ activity, which results in increased thromboxane $A_{2}$ formation 22. Thromboxane $A_{2}$ is a potent aggregating agent and platelet granules content releaser (serotonin, ADP), which perpetuate aggregation phenomenon ${ }^{29}$.

Epinephrine is the primary $\alpha_{2}$-adrenoreceptors agonist, responsible for these pro-aggregating effects in vivo ${ }^{30}$. However, its hemostatic action is complemented by effects on $\alpha_{1}$-adrenoreceptors, responsible for parietal hemostasis phase, or vasoconstriction. On the other hand, pure $\alpha_{2}$-adrenoreceptors stimulation may also promote anti-aggregating effects thru two mechanisms: sympathetic terminations catecholamine release inhibition ${ }^{14}$ and nitric oxide (NO) release ${ }^{31}$.

Sympathetic terminal pre-synaptic membrane $\alpha_{2}$-adrenoreceptors stimulation activates Na-K-ATPase resulting in decreased intracellular $\mathrm{Na}^{+}$and, as a consequence, decreased intracellular $\mathrm{Na}^{+}$exchange by extracellular $\mathrm{Ca}^{2+}$. This decreased $\mathrm{Ca}^{2+}$ concentration within the nervous terminal results in decreased catecholamine release, thus in decreased sympathetic nervous system tone ${ }^{11}$.

It also contributes to anti-platelet aggregation the NO releasing mediated by vascular endothelium $\alpha_{2}$-adrenoreceptors stimulation ${ }^{31,32}$. NO acts through a complex mechanism resulting in increased intracellular cAMP levels. The phosphorilation of cAMP-dependent protein kinase promotes $\mathrm{Ca}^{2+}$ displacement from platelets cytoplasm to its storage site, resulting in contractile proteins relaxation. Platelet returns to its discoid shape and its membrane, again under stress, looses affinity to other membranes, promoting disaggregation ${ }^{29}$.
An in vitro study has shown that dexmedetomidine is almost as effective as epinephrine to induce platelet aggregation ${ }^{13}$. Another in vitro study has shown that NO is able to disaggregate platelets previously aggregated by $\alpha_{2}$-adrenoreceptor agonists ${ }^{31}$.

There are no studies in the literature evaluating the combined effects of pro-aggregating and anti-aggregating factors promoted by $\alpha_{2}$-receptors stimulation. In addition to dexmedetomidine direct effect in decreasing sympathetic tone through catecholamine release inhibition via pre-synaptic $\alpha_{2}$-adrenoreceptors, it is able, as other sedative agents, to indirectly decrease sympathetic tone, simply by the anxiolysis induced by its effects on central nervous system. A study ${ }^{14}$ has shown norepinephrine and cortisol plasma concentration decrease in patients receiving thiopental, propofol and midazolam. Animal studies have also shown catecholamine plasma levels decrease after sedative midazolam doses ${ }^{33,34}$.

The inclusion of group G3 (midazolam) in this study aimed at differentiating dexmedetomidine effects on coagulation as a consequence of direct and/or indirect factors promoted by such drug.

There are several methods to evaluate hemostatic function in humans, all with advantages and disadvantages. Thromboelastography (TEG) was the method of choice for this study ${ }^{16}$.

TEG allows a thorough evaluation of clot formation, structural characteristics and stability of the formed clot. Routine lab tests are performed with centrifuged plasma fractions and assess isolated steps of the coagulation process. The recent understanding of enzyme complexes on the surface of cells involved in the coagulation process and of substances transfer until fibrin formation has led to the discussion about the usefulness of conventional tests, such as Prothrombin Time (PT) and Partial Activated Thromboplastin Time (PATT), in which platelet cell surface (where these phenomena take place) is replaced by other contact factors. TEG uses platelet surface it self to evaluate clot formation, thus being sensitive to platelet function, plasma factors and coagulation activators and inhibitors.

This method has been already used to evaluate propofol effects on coagulation, however samples were incubated in vitro ${ }^{35}$. In our study, dexmedetomidine and midazolam were administered to patients and their effects were evaluated 30 minutes later, enough time for them to exert previously discussed direct and indirect actions. This way, dexmedetomidine effects could be evaluated not only on platelet $\alpha_{2}$-adrenoreceptors, but also on nitric oxide release and sympathetic tone decrease, which are seen in vivo. In our study, both dexmedetomidine and midazolam have not changed thromboelastography parameters more sensitive to platelet changes (Maximum Amplitude - MA and Clot Formation Time - K).

Reaction Time found in all groups, both on initial and final curves, was below normal values. A possible explanation would be the 1-minute delay to begin sample processing, since if this time is considered, $R$ values would be close to nor- 
mality. Most dexmedetomidine group patients have presented final curves with lower coagulation patterns as compared to initial curve; however, only Reaction Time $(R)$ was statistically different, yet keeping above reference lower limit. The difference found is clinically irrelevant. The same applies to Coagulation Index $(\mathrm{Cl})$ evaluation, which decreased in relation to its control, with statistically significant difference. Coagulation Index reflects global coagulation and is the result of the interaction of all clot formation phase parameters measured by thromboelastography. This difference found was limited to statistics, since both initial and final parameters were within reference values. Hence, the interaction of dexmedetomidine pro and anti-aggregating mechanisms was able to change curves toward hypocoagulation; final curves, however, were maintained within normality, showing that, even affecting coagulation, dexmedetomidine has not increased bleeding risk. The midazolam group has behaved differently, suggesting that dexmedetomidine group results were primarily due to its direct effects, since dexmedetomidine and midazolam have shared the same indirect effects on coagulation.

The G2 patient who received a higher maintenance dexmedetomidine dose ( $25 \%$ higher than programmed), as well as the G3 patient receiving additional midazolam dose (30\% higher than initial dose), have not shown different coagulation behaviors as compared to other patients.

As to fibrinolysis phase which starting after reaching maximum amplitude, studied parameters are difficult to interpret because there are no reference values associated to Clot Estimated Percentage Lysis (EPL) and Total Blood Coagulation Lysis (CL30). In the clinical practice, these data are interpreted as from sequential curves behavior. Starting from the same baseline, groups receiving dexmedetomidine or midazolam had lower clot lysis after 30 minutes, as opposed to control group where clot lysis has increased after this period. However, differences between pre and post EPL and CL30 values were not statistically significant. One control group patient was responsible for the high standard deviation of this group in fibrinolysis-related parameters. However, excluding this patient and remaking statistical calculations, all groups were statistically similar.

We have concluded from this study that, after 30-minute continuous infusion, dexmedetomidine anti-coagulant effects have prevailed over pro-coagulating effects. This difference is statistically significant, but without clinical impact since curve values obtained after drug infusion have remained within normal ranges. This effect seems to be promoted by dexmedetomidine direct rather than indirect effects (sedation and anxiolysis), since dexmedetomidine group patients had a different behavior as compared to midazolam group patients, and the latter had a similar behavior as compared to control group.

Both dexmedetomidine and midazolam groups had a trend toward decreasing fibrinolysis phase after 30 minutes as compared to the control group, however, with no statistically and clinically significance.

\section{REFERÊNCIAS - REFERENCES}

01. Hayashi Y, Maze M - Alpha $a_{2}$-adrenoceptor agonists and anesthesia. Br J Anaesth, 1993;71:108-118.

02. Tonner PH, Schlolz J - Clinical perspectives of alpha 2 adrenoceptor agonists. Curr Opin Anaesth, 1996;9:471-480.

03. Aantaa R, Scheinin M - Alpha $a_{2}$-adrenergic agents in anesthesia. Acta Anaesthesiol Scand, 1993;37:433-448.

04. Khan ZP, Ferguson CN, Jones RM - Alpha ${ }_{2}$ and imidazoline receptor agonists, their pharmacology and therapeutic role. Anaesthesia, 1999;54:146-165.

05. MacDonald E, Scheinin M - Distribution and pharmacology of alpha ${ }_{2}$-adrenoceptors in the central nervous system. J Physiol Pharmacol, 1995;46:241-258.

06. Bachand R, Scholz J, Pinaud $M$ et al - The effects of dexmedetomidina in patients in the intensive care setting. Intensive Care Med, 1999;25:(Suppl1):S160.

07. Jalonen J, Markku H - Dexmedetomidine as an anesthetic adjunct in coronary artery bypass grafting. Anesthesiology, 1997;86:331-345.

08. Hynynen M, Jalonen J - Dexmedetomidine infusion improves perioperative adrenergic stability during coronary artery bypass grafting. J Cardiothorac Vasc Surg, 1994;8:(Suppl3):56-62.

09. Fragen RJ, Fitzgerald P, Paul C - The effect of dexmedetomidine on the minimum alveolar concentration (MAC) of sevoflurane in adults age 55 to 70 years to prevent response to skin incision. Anesthesiology, 1998;89:(3AS):134-140.

10. Nunes RR, Cavalcante SL - Influência da dexmedetomidina na concentração expirada do sevoflurano. Avaliação pelo índice bispectral, taxa de supressão e análise espectral da potência do eletroencefalograma. Rev Bras Anestesiol, 2002;52: 133-145.

11. Curtis FG, Castiglia YMM, Stolf AA et al - Dexmedetomidina e sufentanil como analgésicos per-operatórios. Estudo comparativo. Rev Bras Anestesiol, 2002;52:525-534.

12. Bagatini A, Gomes CR, Masella MZ et al - Dexmedetomidina: farmacologia e uso clínico. Rev Bras Anestesiol, 2002;52: 606-617.

13. Grant JA, Scrutton MC - Interaction of selective alpha-adrenoceptor agonists and antagonists with human and rabbit blood platelets. Br J Pharmacol, 1980;71:121-134.

14. Cohen J, Eckstein L, Gutman $Y$ - The mechanism of alpha-adrenergic inhibition of catecholamine realize. $\mathrm{Br} \mathrm{J}$ Pharmacol, 1980;71:135-142.

15. Misioäek H, Wojcieszek E, Dyakzy A et al - Comparison of influence of thiopentone, propofol and midazolam on blood serum concentration of noradrenaline and cortisol in patients undergoing non-toxic struma operation. Med Sci Monit, 2000;6:319-324.

16. Mallett SV, Cox DJA - Thromboelastography. Br J Anaesth, 1992;69:307-313.

17. Gilman AG - G protein: transducers of receptor-generated signal. Ann Rev Biochem, 1987;56:615-649.

18. Birnbaumer L, Abramowitz J, Brown AM - Receptor-effectors coupling by $G$ proteins. Biochemical et Biophysical Acta, 1990;1031:163-224.

19. Codina $\mathrm{J}$ - The subunit of the GTP binding protein $\mathrm{Gk}$ pens atrial potassium channels. Science, 1987;236:442-445.

20. Aghajanian GK, VanderMaelen CP - Alpha ${ }_{2}$ adrenoceptor-mediated hyperpolarization of locus coeruleus neurons: intracellular studies in vivo. Science, 1982;215:1394-1396.

21. Herscheler $H$ - The GTP-binding protein, $G_{0}$, regulates neuronal calcium channels. Nature, 1987;325:445-447.

22. Isom LL, Cragoe Jr EJ, Limbird LE - Alpha ${ }_{2}$ adrenergic receptors accelerate $\mathrm{Na}^{+} / \mathrm{H}^{+}$exchange in neuroblastoma $x$ glioma cells. J Biol Chem 1987;262:6720-6787. 


\section{EFFECTS OF DEXMEDETOMIDINE ON BLOOD COAGULATION \\ EVALUATED BY THROMBOELASTOGRAPHY}

23. Bylund DB - Heterogeneity of alpha ${ }_{2}$ adrenergic receptors. Pharmacol, Biochem Behavior 1985;22:835-843.

24. Lidbrink P - The effect of lesion of ascending noradrenergic pathways on sleeping and awaking in rats. Brain Research, 1974;74: 19-40.

25. Belleville JP, Wards DS, Bloor BC et al - Effects of intravenous dexmedetomidine in humans. I Sedation, ventilation, and metabolic rate. Anesthesiology, 1992;77:1125-1133.

26. Bloor BC, Wards DS, Belleville JP et al - Effects of intravenous dexmedetomidine in humans. II Hemodynamic changes. Anesthesiology, 1992;77:1134-1142.

27. Dyck JB, Shafer SL - Dexmedetomidine pharmacokinetics and pharmacodynamics. Anaesth Pharm Review, 1993;1:238-245.

28. Clare KA, Scrutton MC, Thompson NT - Effects of alpha $_{2}$-adrenoceptor agonists and of related compounds on aggregation of, and on adenylate cyclase activity in, human platelets. Br J Pharmacol, 1984;82:467-476.

29. Almeida TV - Hemostasia, em: Aires MM - Fisiologia, $1^{\text {a }}$ Ed, 1991;1:94-108.

30. Clare KA, Scrutton MC - Interactions of human platelets with plasma adrenoceptor agonists. $\mathrm{Br} \mathrm{J}$ Pharmacol, 1984;78: 158-166.

31. Radomsky MW, Palmer RMJ, Moncada S - The anti-aggregating properties of vascular endothelium: interactions between prostacyclin and nitric oxide. Br J Pharmacol, 1987;92:639-646.

32. Azuma H, Ishikawa M, Sekizaki S - Endothelium-dependent inhibition of platelet aggregation. $\mathrm{Br} \mathrm{J}$ Pharmacol, 1990;88: 411-415.

33. Kubota T, Hirota K, Yoshida S et al - Effects of sedatives on noradrenaline release from the medial prefrontal cortex in rats. Psychopharmacol, 1999;148:335-338.

34. Kobayashi $Y$, Muldoon SM, Kiyose $M$ et al - Inhibition by midazolam of the adrenergic function in the isolated canine mesenteric vein. Acta Anaesthesiol Scand, 1998;42: 1157-1163.

35. Kohro S, Yamakage M, Omote T et al - In vitro effects of propofol on blood coagulability and fibrinolysis by the use of thromboelastography technique. Acta Anaesthesiol Scand, 1999;43:217-219.

\section{RESUMEN}

Martins CR, Tardelli MA, Amaral JLG - Efectos de la Dexmedetomidina sobre la Coagulación Sanguínea Evaluada a través del Método de la Tromboelastografía

JUSTIFICATIVA Y OBJETIVOS: La dexmedetomidina es un agente agonista de los receptores adrenérgicos $\alpha_{2}$ altamente selectivo, usado en anestesia por sus efectos hipnoanalgésicos y por la estabilidad cardiovascular. El estímulo de los receptores adrenérgicos $\alpha_{2}$ puede presentar efectos pro y antiagregantes plaquetarios, por mecanismos directos e indirectos. En este estudio, se evaluaron los efectos de la dexmedetomidina sobre la coagulación a través del método de la tromboelastografia.

MÉTODO: Veinticuatro pacientes fueron aleatoriamente divididos en tres grupos. Los pacientes del grupo 1 recibieron infusión de solución fisiológica (control), los del grupo 2 recibieron dexmedetomidina en la dosis de $1 \mu \mathrm{g} . \mathrm{kg}^{-1}$ en 10 minutos, seguida de infusión de $0,4 \mu \mathrm{g} \cdot \mathrm{kg}^{-1} \cdot \mathrm{h}^{-1}$ por 20 minutos y los del grupo 3 recibieron midazolam en dosis de $0,05 \mathrm{mg}_{\mathrm{kg}}{ }^{-1}$. Los pacientes sedados mantuvieron índices 3 ó 4 en la escala de la sedación de Ramsay. Fueron colectadas muestras de sangre y se obtuvieron trazados de tromboelastografía previamente y después de 30 minutos del tratamiento.

RESULTADOS: La dexmedetomidina, de forma estadísticamente significativa, aumentó el tiempo de reacción (parámetro R) y diminuyó el índice de coagulación en los trazados finales en relación a los iniciales. No obstante, los valores permanecieron dentro de los intervalos considerados normales. Este fenómeno no fue observado en los demás grupos.

CONCLUSIONES: La interacción de los mecanismos pro y antiagregantes de la dexmedetomidina lleva a una discreta hipocoagulación; sin embargo, mantiene la coagulación dentro de parámetros considerados normales. Los efectos de la dexmedetomidina sobre la coagulación probablemente no ocurren pela ansiólisis, una vez que la sedación fue igual al grupo que recibió midazolam. 